ARTICLE

DOI: $10.1038 / s 41467-018-05782-5$

\title{
Intracellular interleukin-32 $\gamma$ mediates antiviral activity of cytokines against hepatitis B virus
}

\author{
Doo Hyun Kim¹, Eun-Sook Park ${ }^{1}$, Ah Ram Lee ${ }^{1}$, Soree Park ${ }^{1}$, Yong Kwang Park 1 , Sung Hyun Ahn , \\ Hong Seok Kang${ }^{1}$, Ju Hee Won', Yea Na Ha', ByeongJune Jae, Dong-Sik Kim @ ${ }^{2}$, Woo-Chang Chung ${ }^{3}$, \\ Moon Jung Song ${ }^{3}$, Kee-Hwan Kim ${ }^{4}$, Seung Hwa Park ${ }^{5}$, Soo-Hyun Kim ${ }^{6}$ \& Kyun-Hwan Kim,7
}

Cytokines are involved in early host defense against pathogen infections. In particular, tumor necrosis factor (TNF) and interferon-gamma (IFN- $\gamma$ ) have critical functions in non-cytopathic elimination of hepatitis B virus (HBV) in hepatocytes. However, the molecular mechanisms and mediator molecules are largely unknown. Here we show that interleukin-32 (IL-32) is induced by TNF and IFN- $\gamma$ in hepatocytes, and inhibits the replication of HBV by acting intracellularly to suppress HBV transcription and replication. The gamma isoform of IL-32 (IL$32 \gamma$ ) inhibits viral enhancer activities by downregulating liver-enriched transcription factors. Our data are validated in both an in vivo HBV mouse model and primary human hepatocytes. This study thus suggests that IL-32 $\gamma$ functions as intracellular effector in hepatocytes for suppressing HBV replication to implicate a possible mechanism of non-cytopathic viral clearance.

\footnotetext{
${ }^{1}$ Department of Pharmacology and Center for Cancer Research and Diagnostic Medicine, IBST, School of Medicine, Konkuk University, Seoul 05029, Republic of Korea. ${ }^{2}$ Division of HBP Surgery and Liver Transplantation, Department of Surgery, Korea University College of Medicine, Seoul 02841, Republic of Korea. ${ }^{3}$ Virus-Host Interactions Laboratory, Division of Biotechnology, Department of Biosystems and Biotechnology, College of Life Sciences and Biotechnology, Korea University, Seoul 02841, Republic of Korea. ${ }^{4}$ Department of Surgery, Uijeongbu St. Mary's Hospital, Catholic Central Laboratory of Surgery, College of Medicine, The Catholic University of Korea, Seoul 11765, Republic of Korea. ${ }^{5}$ Department of Anatomy, School of Medicine, Konkuk University, Seoul 05029, Republic of Korea. ${ }^{6}$ Laboratory of Cytokine Immunology, Veterinary School, Konkuk University, Seoul 05029, Republic of Korea. ${ }^{7}$ KU Open Innovation Center, Research Institute of Medical Sciences, Konkuk University, Seoul 05029, Republic of Korea. These authors contributed equally: Doo Hyun Kim, Eun-Sook Park. Correspondence and requests for materials should be addressed to K.-H.K. (email: khkim10@kku.ac.kr)
} 
nfection with hepatitis $\mathrm{B}$ virus (HBV) is responsible for global public health problems including chronic hepatitis $\mathrm{B}$, liver cirrhosis, and hepatocellular carcinoma. HBV clearance during acute HBV infection is mainly mediated by antiviral cytokines secreted by cytotoxic $\mathrm{T}$ lymphocytes without damage to infected hepatocytes, a phenomenon dubbed non-cytopathic clearance $e^{1-3}$. Various cytokines inhibit HBV gene expression and replication through diverse mechanisms in vitro and in vivo ${ }^{4,5}$. Tumor necrosis factor-alpha (TNF- $\alpha$ ) reduces HBV RNA production and capsid stability ${ }^{1-3,6}$. Interferon-gamma (IFN- $\gamma$ ) eliminates pregenomic RNA-containing capsids in mouse hepatocytes ${ }^{5}$. Interleukin (IL)-4 inhibits $\mathrm{HBV}$ transcription by downregulating CCAAT/enhancer-binding protein $(\mathrm{C} / \mathrm{EBP})^{7}$.

TNF- $\alpha$ and IFN- $\gamma$ are representative antiviral cytokines that suppress HBV in a non-cytolytic manner ${ }^{1,3,8}$. Recently, $\mathrm{T}$ cellderived TNF- $\alpha$ and IFN- $\gamma$ were found to reduce HBV covalently closed circular DNA (cccDNA) in hepatocytes by inducing APOBEC3 deaminases ${ }^{9}$. We also reported that P22-FLIP ${ }^{10}$ and hepatocystin $^{11}$ are involved in TNF- $\alpha$-mediated and IFN- $\gamma$ mediated suppression of $\mathrm{HBV}$, respectively. However, the precise mechanism and downstream mediator molecules involved in HBV suppression by TNF- $\alpha$ and IFN- $\gamma$ have not been clearly elucidated.

IL-32 was discovered as a proinflammatory cytokine that is secreted from natural killer (NK) cells and activates mitogenactivated protein kinases (MAPKs) and NF- $\kappa B$ signaling pathways $^{12,13}$. It is produced by various epithelial and immune cells such as T lymphocytes, NK cells, and monocytes. In the pancreas, it is induced by cytokines ${ }^{14}$. The IL-32 gene is transcribed into six alternative splice variants; among them, IL-32 $\gamma$ is the most active form ${ }^{15}$. However, the biological function of IL-32 isoforms in specific tissues remains unclear.

Treatment with recombinant IL-32 suppresses replication of various viruses through autocrine or paracrine mechanisms (i.e., IL-32 acts as a typical cytokine); the viruses suppressed by IL-32 include vesicular stomatitis virus (VSV) ${ }^{16,17}$, human immunodeficiency virus $(\mathrm{HIV})^{18,19}$, and influenza virus ${ }^{20-22}$. Interestingly, treatment of peripheral blood mononuclear cells with recombinant IL-32-induced IFN- $\lambda 1$, which in turn inhibited HBV replication in hepatocytes ${ }^{23}$. However, the direct antiviral action of IL-32 in hepatocytes has not been demonstrated.

Transcription of HBV cccDNA in the nucleus requires liverenriched transcription factors such as hepatocyte nuclear factors (HNFs) and C/EBP, which bind to HBV enhancer I (EnhI) and II (EnhII) regions ${ }^{24,25}$. The expression of these factors is regulated mainly by MAPK signaling pathways ${ }^{26,27}$. Here we show that TNF- $\alpha$ and IFN- $\gamma$ synergistically induce IL-32, which suppresses HBV by downregulating liver-enriched transcription factors in a non-cytokine-like manner. Our novel finding suggests a mechanism of cytokine-mediated non-cytopathic clearance of HBV.

\section{Results}

Cytokine-induced intracellular IL-32 inhibits HBV replication. As HBV-specific CD8+ cytotoxic T cells suppress viral replication by releasing TNF- $\alpha$ and IFN- $\gamma^{4}$, we tested whether these antiviral cytokines induce the expression of IL-32. Treatment of Huh7 cells with either TNF- $\alpha$ or IFN- $\gamma$ upregulated the IL-32 protein in a dose-dependent manner. Surprisingly, co-treatment with TNF- $\alpha$ and IFN- $\gamma$ strongly induced endogenous IL-32 in a synergistic manner (Fig. 1a, left). Upon treatment with these cytokines, cells remained intact (Fig. 1a, right). Immunofluorescence analysis confirmed that the IL-32 protein is induced by the cytokines and revealed that it is mostly localized in the cytoplasm. Ectopic expression of IL-32 was used as a positive control (Fig. 1b).
To assess the anti-HBV effect of TNF- $\alpha$ and IFN- $\gamma$, Huh7 cells were transfected with HBV 1.2 and treated with these cytokines. As expected, Southern blot analysis showed that co-treatment with TNF- $\alpha$ and IFN- $\gamma$ synergistically inhibited HBV replication (Fig. 1c, left). Under this condition, the expression of IL-32 was strongly induced without loss of cell viability (Fig. 1c, right). To test whether cytokine-induced IL-32 is involved in the anti-HBV effect of TNF- $\alpha$ and IFN- $\gamma$, we knocked down IL-32 in Huh7 and HepG2 cells and confirmed it is silencing by western blot analysis (Supplementary Fig. 1). In both cell lines, the knockdown restored $\mathrm{HBV}$ replication inhibited by cytokine treatment (Fig. 1d).

Because IL-32 was discovered as a cytokine secreted by NK cells $^{12,13}$, we tested whether the induced IL-32 exerts its anti-HBV effect through an autocrine or paracrine effect. To check this, Huh7 and HepG2 cells transfected with HBV 1.2mer were incubated with the recombinant human IL-32 $\gamma$ (rhIL-32 $\gamma$ ). Unexpectedly, this treatment had no effect on HBV replication in both cell lines (Fig. 1e). The biological activity of rhIL-32 $\gamma$ was confirmed by its ability to induce IL- 8 and TNF- $\alpha$ in human THP-1 and murine Raw 264.7 cells, which was reported previously ${ }^{15}$ (Supplementary Fig. 2). These unexpected results prompted us to check whether cytokine-induced IL-32 is secreted or not. Surprisingly, it was mostly retained in the cells and was rarely detected in culture supernatants of Huh7 hepatoma cells (Fig. 1f). To check whether the intracellular retention of IL-32 is physiologically relevant, we treated $\mathrm{PHH}$ s and differentiated HepaRG cells with TNF- $\alpha$ and IFN- $\gamma$. The results clearly revealed that IL-32 was not secreted from hepatocytes (Fig. 1g, Top HepaRG; Bottom PHHs).

Taken together, these findings suggest that IL-32 mediates the anti-HBV activity of TNF- $\alpha$ and IFN- $\gamma$ as a non-cytokine-like molecule in hepatocytes.

Intracellular antiviral effect of IL-32 is specific to HBV. To confirm that the IL-32 $\gamma$-mediated inhibition of HBV replication is an intracellular event, we co-transfected Huh7 cells with HBV 1.2 and IL-32 $\gamma$ expression plasmids. Overexpression of IL-32 strongly inhibited HBV replication (by approximately 90\%) with no evidence of cytotoxicity (Fig. 2a). As in the experiments described above, little IL-32 $\gamma$ was secreted when it was overexpressed (Fig. 2b). When IL-32 $\gamma$ was overexpressed in HepG2, L02, and Hep3B cells, it also strongly inhibited HBV replication (Supplementary Fig. 3a-d). To confirm the direct inhibitory effect of overexpressed IL-32 $\gamma$ on viral replication, we knocked down IL-32 $\gamma$ by using siRNA. Silencing of IL-32 completely restored HBV replication (Supplementary Fig. 3b).

In addition, we tested which isoform of IL-32 is most active in inhibiting $\mathrm{HBV}$ replication. Although all three IL-32 isoforms tested (IL-32 $\alpha$, IL-32 $\beta$, and IL-32 $\gamma$ ) inhibited HBV replication, IL$32 \gamma$ had the most potent anti-HBV activity (Fig. 2c, d).

Next, we investigated whether the antiviral effect of IL-32 $\gamma$ is mediated by the induction of general antiviral pathways, such as innate immune responses, or is specific to $\mathrm{HBV}$. We infected Huh7 cells with herpes simplex virus 1 (HSV-1_GFP) or influenza A virus (A/WSN/33_GFP) and assayed the effect of IL-32 $\gamma$ on viral growth. Ganciclovir (GCV) and a combination of IFN- $\alpha$ and IFN $-\gamma$ were used as positive control antiviral agents for each virus. First, we found that $\mathrm{HSV}-1$ is insensitive to a combination of TNF- $\alpha$ and IFN- $\gamma$, which inhibits HBV replication; however, influenza virus was sensitive to these cytokines (Fig. 2e, f). Analysis of GFP signals and viral titration showed that IL-32 $\gamma$ expression did not affect the replication of HSV-1 or influenza virus in Huh7 cells (Fig. 2e-h). Analysis of viral transcription, protein expression, and titration (Supplementary 
a

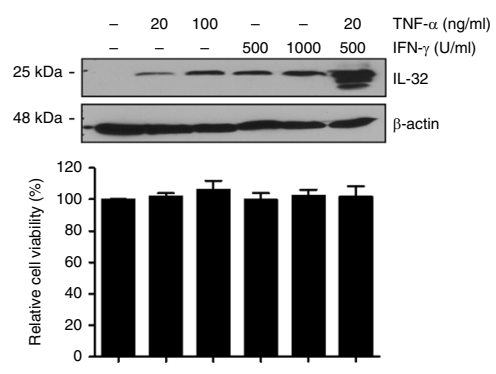

C
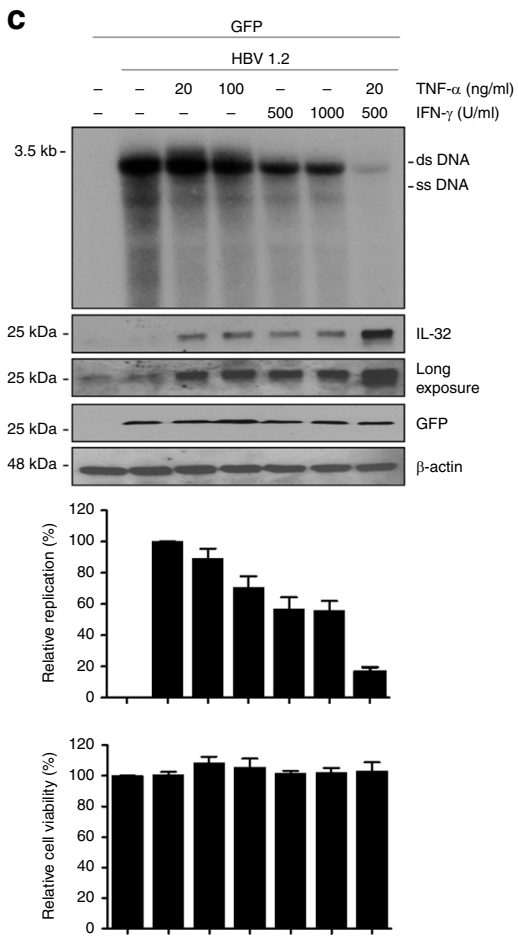

f

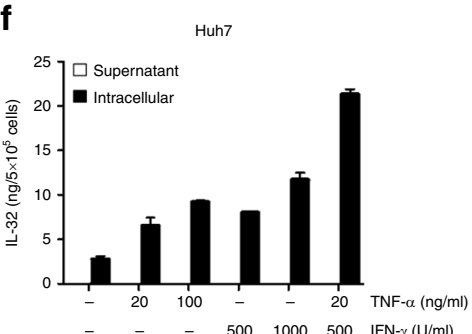

g b

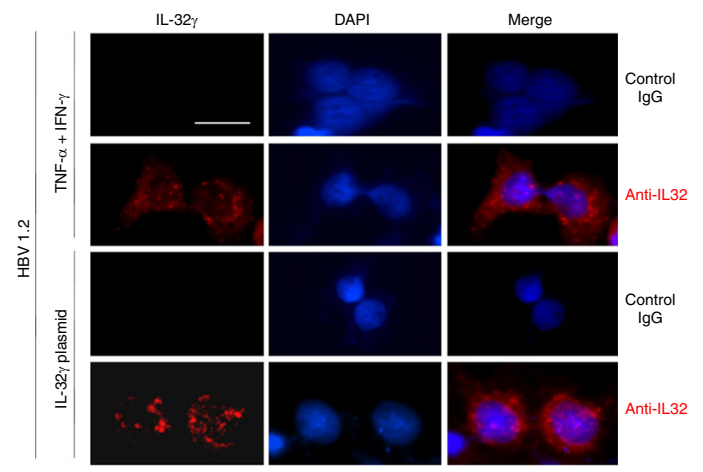

d
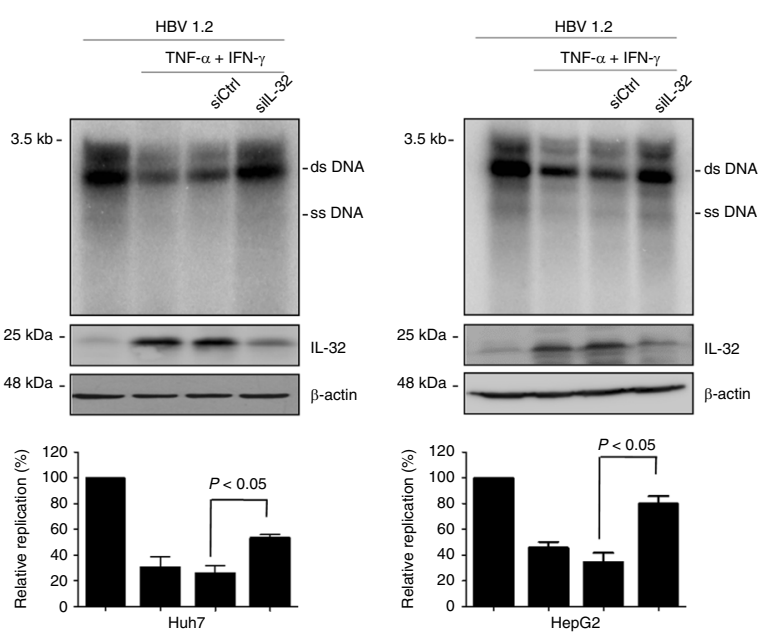

e
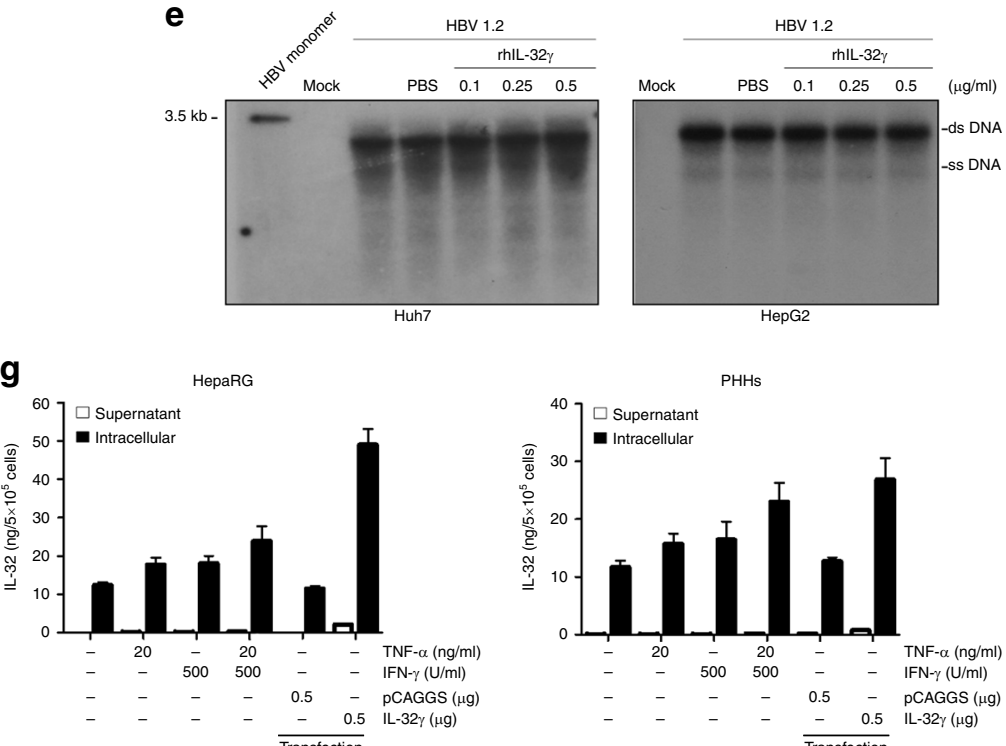

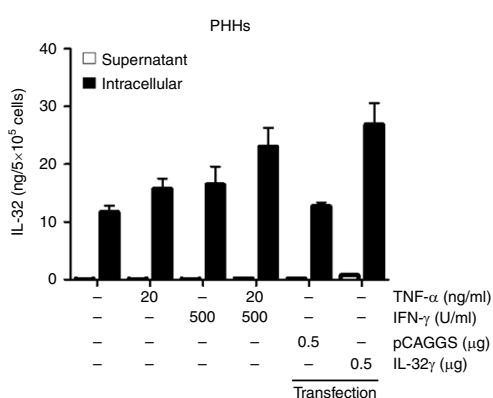

Fig. 1 Induction of IL-32 is involved in cytokine-mediated inhibition of HBV. a Huh7 cells were treated with the indicated concentrations of TNF- $\alpha$ and IFN- $\gamma$ for $48 \mathrm{~h}$, and the IL-32 level was determined by western blot analysis. Relative cell viability was measured by the XTT method. $\mathbf{b}$ Expression of IL-32 $\gamma$ induced by cytokines or transient transfection was observed by immunofluorescence assay. Magnification, $\times 400$; scale bar, $50 \mu \mathrm{m}$. c Huh7 cells were transfected with the HBV 1.2 and GFP plasmids and treated with TNF- $\alpha$ and IFN- $\gamma$. HBV replication was determined by Southern blotting. Expression levels of IL-32 and GFP (transfection control) were determined by western blotting. d HBV 1.2 and siRNAs (20 nM) were co-transfected into Huh7 or HepG2 cells. Next day, cytokines were added with fresh medium. HBV replication and IL-32 expression were determined by Southern and western blotting, respectively. $p<0.05$ by Student's $t$-test. e Huh7 or HepG2 cells were transfected with the HBV 1.2 plasmid and treated with recombinant human IL-32 $\gamma$ (rhIL-32 $\gamma$ ) for 3 days. HBV replication was determined by Southern blotting. $\mathbf{f}$ The levels of the IL-32 protein in culture medium and lysates of cytokinetreated Huh7 cells were determined by ELISA. The total amount of secreted (supernatant) or intracellular IL-32 in whole cells grown in a 12-well plate are shown. $\mathbf{g}$ The levels of the IL-32 protein in culture medium and lysates of cytokine-treated PHHs and differentiated HepaRG cells were determined by ELISA. Dashed bars represent the level of IL-32 obtained after transfection with pCAGGS (control) or IL-32 plasmids. Data (a, c, d, $\mathbf{f}, \mathbf{g}$ ) were obtained from three independent experiments (mean \pm S.D.). $p<0.05$ by Student's $t$-test 
a
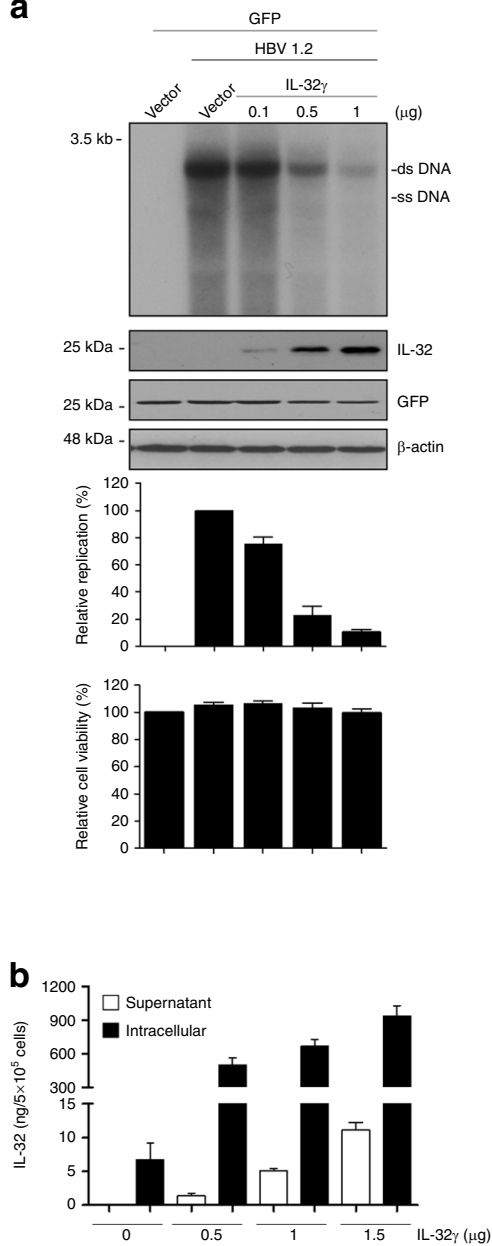

C

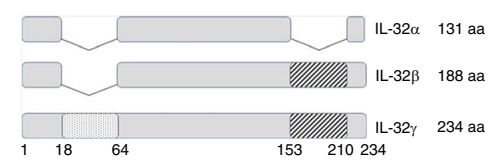

d
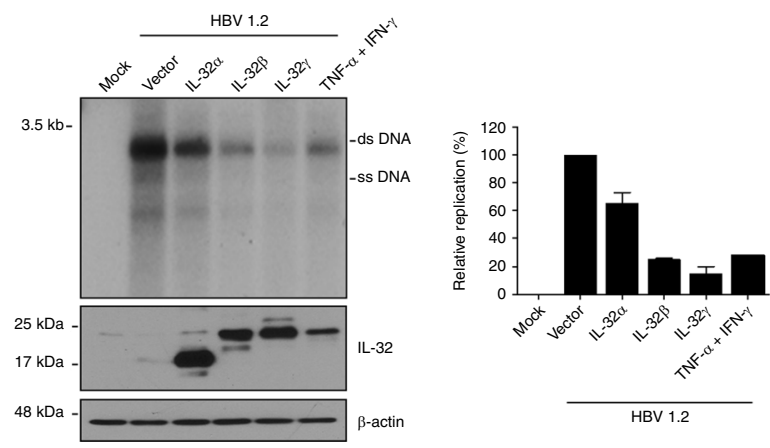

e
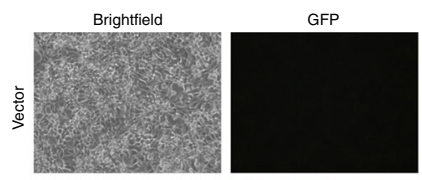

f
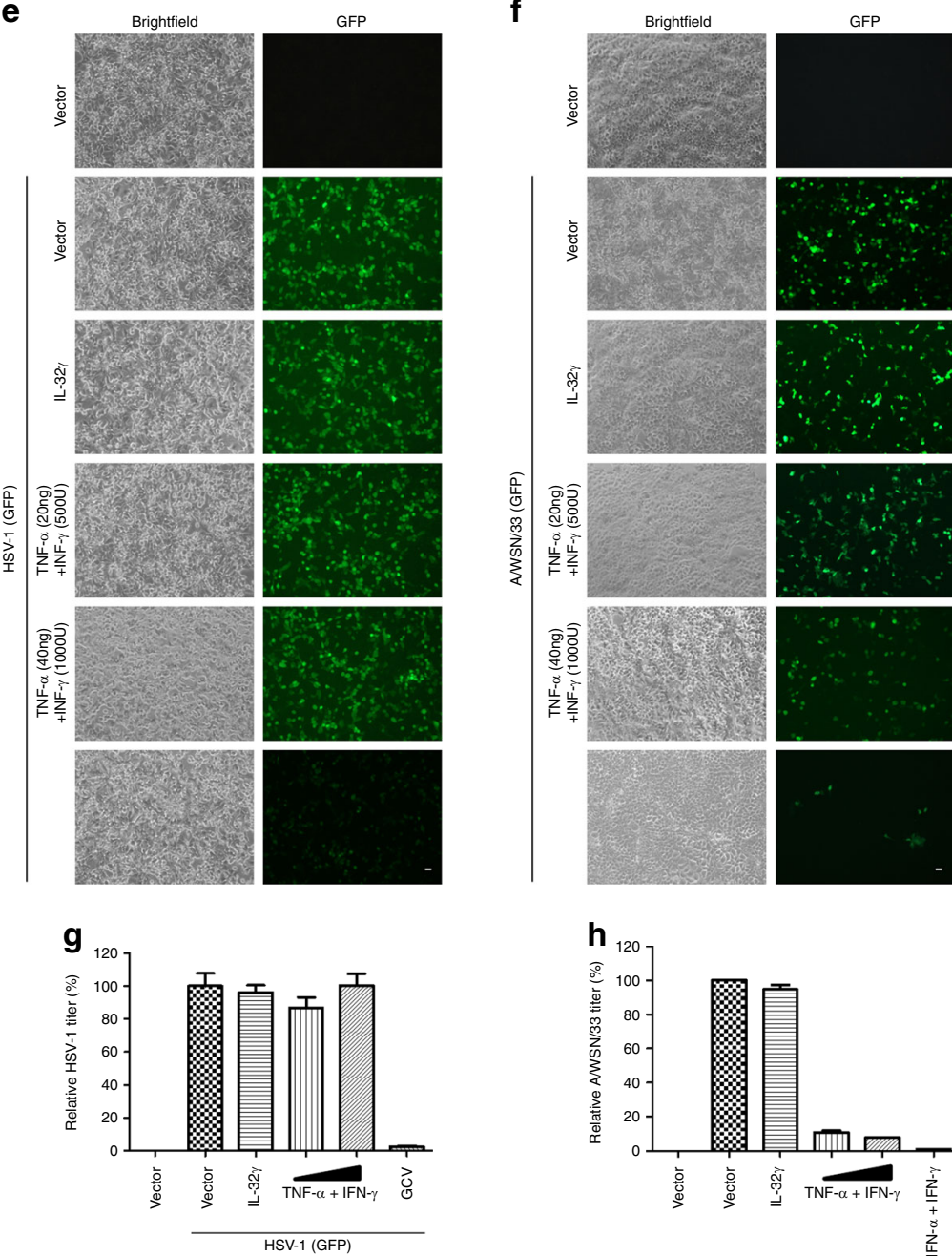
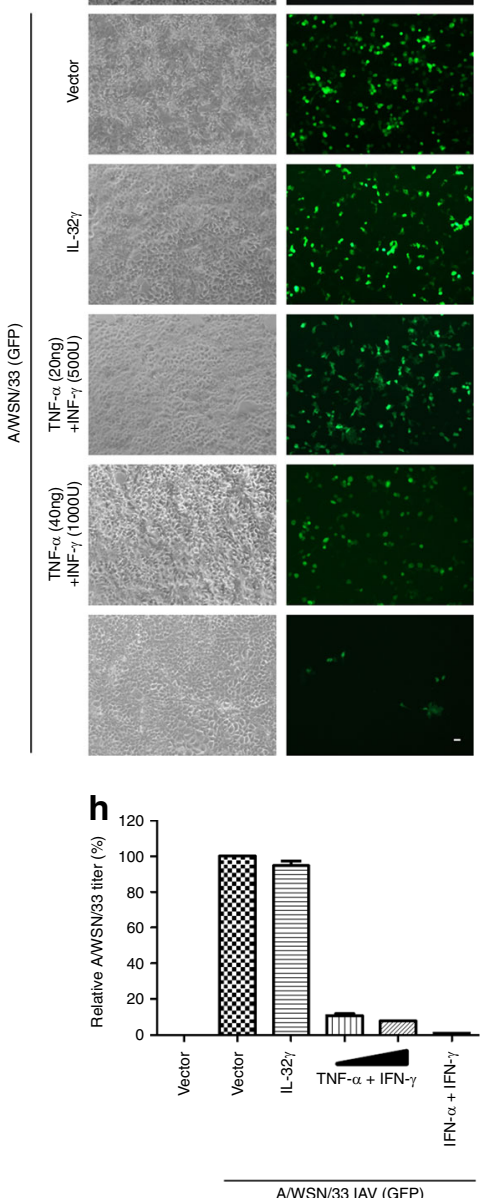

Fig. 2 Inhibition of HBV replication by IL-32 $\gamma$ through an intracellular event and the effect of IL-32 $\gamma$ on other viruses. a Vectors for HBV 1.2 and IL-32 $\gamma$ were co-transfected into Huh7 cells. At $48 \mathrm{~h}$ post-transfection, viral replication, protein expression, and cell viability were analyzed by Southern blotting, western blotting, and XTT assay, respectively. $\mathbf{b}$ The levels of the IL-32 protein in culture medium and lysates of IL-32 $\gamma$-transfected Huh7 cells were measured by ELISA. c Schematic illustration of IL-32 isoforms. Shaded boxes represent the N-terminal and C-terminal extensions in IL-32 $\gamma$. d Vectors for HBV 1.2, IL-32 $\alpha$, IL-32 $\beta$, or IL-32 $\gamma$ were transfected in Huh7 cells as indicated. At $48 \mathrm{~h}$ post-transfection, viral replication and protein expression were analyzed by Southern and western blotting, respectively. Cells treated with cytokines were used as a control. e-h IL-32 expression vector or empty vector was transfected into Huh7 cells. After $16 \mathrm{~h}$, cells were infected with herpes simplex virus 1 (HSV-1_GFP) or influenza A virus (A/WSN/33_GFP) at 1 MOI. Cells were treated with the indicated concentrations cytokines (TNF- $\alpha$ and IFN- $\gamma$ ). Treatment with GCV $(1 \mu \mathrm{g} / \mathrm{mL})$ or IFNs $(1000 \mathrm{U} / \mathrm{mL}$ IFN- $\alpha$ and $100 \mathrm{U} / \mathrm{mL}$ IFN- $\gamma$ ) was used as a positive control for HSV-1 and A/WSN/33, respectively. The GFP signals were monitored at $24 \mathrm{~h}$ post-infection. Magnification, $\times 100$; scale bar, $100 \mu \mathrm{m}$. Data $(\mathbf{a}, \mathbf{b}, \mathbf{d}, \mathbf{g}, \mathbf{h})$ were obtained from three independent experiments (mean \pm S.D.) 
Figs. 4 and 5) also indicated that IL-32 $\gamma$ exerts no effect on replication of HSV-1 or influenza virus. Indeed, ectopically expressed IL-32 $\gamma$ did not induce the antiviral cytokines and cytokine-induced antiviral genes in hepatocytes (Supplementary Fig. 6). These results suggest that IL-32 $\gamma$-mediated inhibition of $\mathrm{HBV}$ replication is virus-specific in hepatocytes.

IL-32 $\gamma$ suppresses $\mathrm{HBV}$ at transcriptional level. To identify at which step of the HBV life cycle IL-32 $\gamma$ interferes, we first analyzed viral transcription using Northern blot analysis. Transfection with IL-32 $\gamma$ inhibited the expression of HBV mRNAs in a dose-dependent manner (Fig. 3a). Accordingly, the levels of viral proteins such as the surface and core proteins were remarkably reduced by IL-32 $\gamma$ (Fig. $3 \mathrm{~b}$ ). As the transcription of the HBV genome is mainly regulated by EnhI and by EnhII, which overlaps with the core promoter (EnhII/Cp), we determined which enhancer is targeted by IL-32 $\gamma$. We generated reporter plasmids containing deletion mutants of the enhancer regions (Fig. 3c) and determined their activities in the absence or presence of IL-32 $\gamma$. Reporter assay showed that EnhI had much higher activity than EnhII/Cp when IL-32 $\gamma$ was absent. The activities of all enhancer reporters were markedly decreased (by $\sim 90 \%$ ) by IL-32 $\gamma$, suggesting that IL-32 $\gamma$ suppresses both EnhI and EnhII/Cp simultaneously (Fig. 3d).

As these results suggest that IL-32 inhibits $\mathrm{HBV}$ at the transcriptional level, we first determined the effect of IL-32 knockdown on cytokine-induced suppression of HBV by Northern blot analysis (Fig. 3e). The cytokine-induced decrease in HBV RNAs was significantly reverted by IL-32 knockdown in human hepatocytes (Fig. 3e). The steady-state level of HBV transcription was suppressed by both IL-32 $\gamma$ and IFN- $\gamma$ in the nuclear and cytoplasmic compartments (Fig. 3f). Furthermore, nuclear run-on assay revealed that the rate of HBV transcription was decreased by IL-32 $\gamma$ and IFN- $\gamma$ (Fig. 3g). Together with IL-32-mediated inhibition of enhancer activity (Fig. 3d), our data suggest that cytokines inhibit HBV at the transcriptional level by inducing IL32 , consistent with our and other previous studies which found that cytokines inhibit HBV at the transcriptional level in human hepatocytes ${ }^{10,28,29}$.

As it is well known that IFN- $\gamma$ inhibits $\mathrm{HBV}$ at the posttranscriptional level in a mouse model ${ }^{30}$, we freshly prepared PMHs from mouse liver and analyzed the effect of cytokines on HBV replication and antigen expression. The level of viral RNA and antigen secretion were decreased by cytokines and IL-32 $\gamma$ in PMHs (Supplementary Fig. 7).

Next, we checked whether the SSB/La protein level is affected by cytokine treatment or IL-32 $\gamma$ expression because the stability of HBV RNA is reduced by cytokine-induced depletion of the La protein in a mouse model ${ }^{31-33}$. Indeed, cytokines destabilized the La protein in PMHs; however, they showed little effect in Huh7 human cells (Supplementary Fig. 7). Importantly, the level of the La protein was not affected by overexpression of IL-32 $\gamma$ in either cell type, suggesting that cytokine-induced IL-32 downregulates HBV RNA in a La-independent manner.

To further confirm the La-independence in human hepatocytes, we determined the levels of HBV RNAs after a knockdown of La expression (Supplementary Fig. 8). In Huh7 cells, La knockdown had no effect on the levels of HBV RNAs, whereas IL-32 strongly reduced them (Supplementary Figs. 8 and 9). However, LA knockdown in PMHs significantly decreased the levels of HBV RNAs and antigens (Supplementary Fig. 9). These data suggest that cytokines suppress HBV RNAs at the posttranscriptional level through a La-dependent pathway in PMHs but at the transcriptional level through a La-independent pathway in human hepatocytes.
IL-32 $\gamma$ decreases HNFs expression. HBV transcription is regulated by binding of liver-enriched transcription factors to enhancers and the core promoter ${ }^{7,25,34}$. As IL-32 $\gamma$ suppresses both EnhI and EnhII/Cp simultaneously, we hypothesized that the transcription factors that bind to both regions are targeted by IL-32 $\gamma$. A literature search revealed that several ubiquitous and liver-enriched transcription factors bind to both EnhI and EnhII/ $\mathrm{Cp}^{27,35}$. Among those, we focused on the major liver-enriched transcription factors known to be involved in HBV transcription including C/EBP, HNF1, HNF3, and HNF4 (Fig. 4a).

Ectopic expression of IL-32 $\gamma$ or treatment with cytokines reduced the expression of HNF1a and HNF4a at both the mRNA and protein levels, while they failed to significantly affect $\mathrm{C} / \mathrm{EBPa}$ or HNF3 $\beta$ expression in the presence of HBV (Fig. $4 \mathrm{~b}-\mathrm{d}$ ). Furthermore, confocal microscopy analysis demonstrated that only the cells expressing a high amount of IL-32 $\gamma$ showed the decreased levels of HNF1 $\alpha$ and HNF4 $\alpha$ expression (Fig. 4e, f).

Because the binding of HNF1 $\alpha$ and HNF4a to HBV enhancers is essential for promoting viral transcription and replication ${ }^{25}$, we tested whether the decrease in the levels of HNF1a and HNF4a induced by IL-32 $\gamma$ reduces their binding to cognate enhancer regions. We performed a ChIP assay using antibodies against HNF1 $\alpha$ and HNF4a. Interestingly, our data revealed that HNF4a binding to the EnhI region was markedly reduced by IL-32 $\gamma$, while its binding to EnhII/Cp was not affected (Fig. 4g). On the contrary, HNF1a binding to the EnhI region was not affected by IL-32 $\gamma$, while its binding to EnhII/Cp was markedly reduced (Fig. 4h). To confirm that the binding of HNF4a to the EnhI region is altered in the presence of IL-32 $\gamma$, we performed an EMSA. Similar to the results of the ChIP assay, we found that IL$32 \gamma$ strongly reduced the binding of HNF4a to the EnhI region (Fig. 4i). The formation of the DNA-HNF4a complex was confirmed by western blotting. Taken together, our data suggest that IL-32 $\gamma$ decreases the expression of both HNF1 $\alpha$ and HNF4a and consequently reduces their binding to viral enhancers.

IL-32 $\gamma$ downregulates HNF4a through ERK1/2 pathways. To elucidate the molecular mechanism by which IL-32 $\gamma$ downregulates the expression of HNF1 $\alpha$ and $\mathrm{HNF} 4 \alpha$, we examined its effects on the signaling pathways related to HNF expression. As the expression of liver-enriched transcription factors is regulated by the MAPK signaling pathway ${ }^{26,36}$, we investigated whether this pathway is involved in IL-32 $\gamma$-mediated downregulation of HNF1 $\alpha$ and HNF4a. Both IL-32 $\gamma$ overexpression and cytokine treatment strongly activated extracellular signal-regulated kinase (ERK)1/2 signaling but did not affect the phosphorylation of Jun $\mathrm{N}$-terminal kinase (JNK) or p38 (Fig. 5a). Activation of ERK1/2 by IL-32 $\gamma$ correlated with the decreased expression of HNF1 $\alpha$ and HNF4a. Furthermore, treatment with U0126, an inhibitor of the ERK1/2 pathway, completely restored the HNF4a expression and partially restored HNF1a expression (Fig. 5b).

Next, we determined the downregulation of which HNF is dominant in IL-32 $\gamma$-mediated suppression of HBV. Supplementation with HNF4a almost completely restored viral replication (Fig. 5c), whereas supplementation with HNF1a only partially restored it (Fig. 5d). We further examined whether activation of ERK1/2 is involved in IL-32 $\gamma$-mediated inhibition of $\mathrm{HBV}$ replication. Chemical inhibition of ERK1/2 activation markedly blunted the IL-32 $\gamma$-mediated inhibition of viral replication (Fig. 5e), indicating that IL-32 $\gamma$ suppresses $\mathrm{HBV}$ replication through activation of the ERK1/2 pathway.

Taken together, our data demonstrate that IL-32 $\gamma$ downregulates the expression of HNF1 $\alpha$ and HNF4 $\alpha$ via the MAPK/ ERK pathway, and that the reduced expression of HNF4a is the 
a

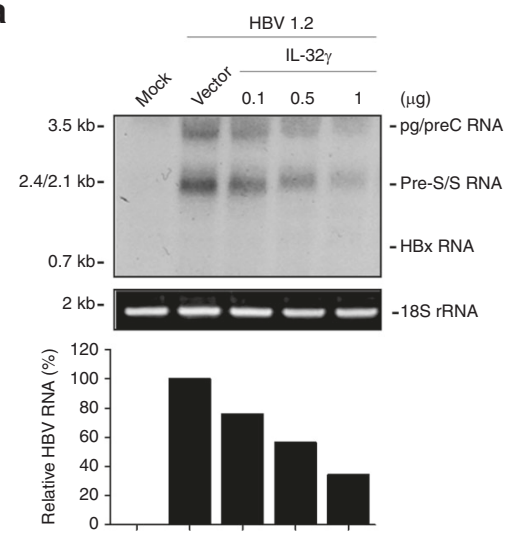

C

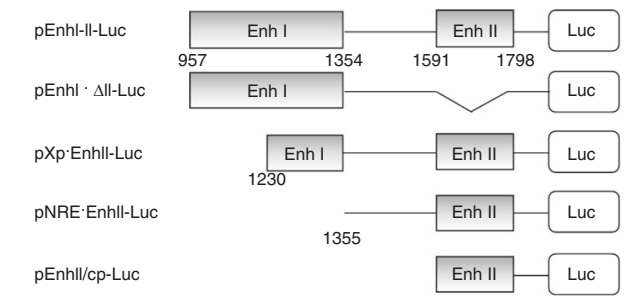

e

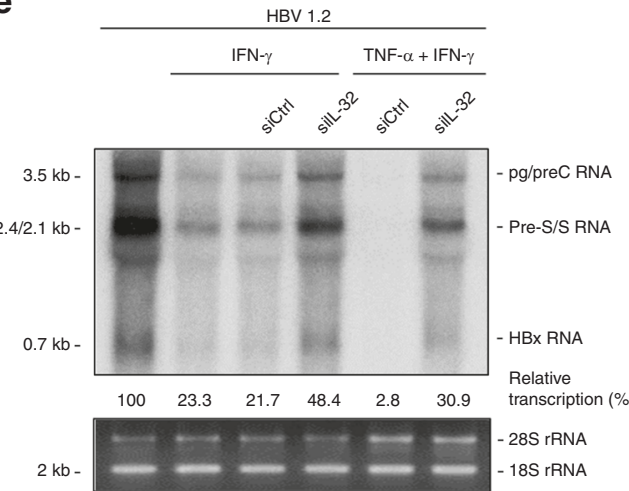

b

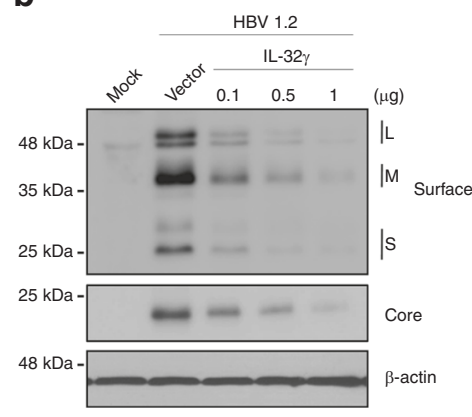

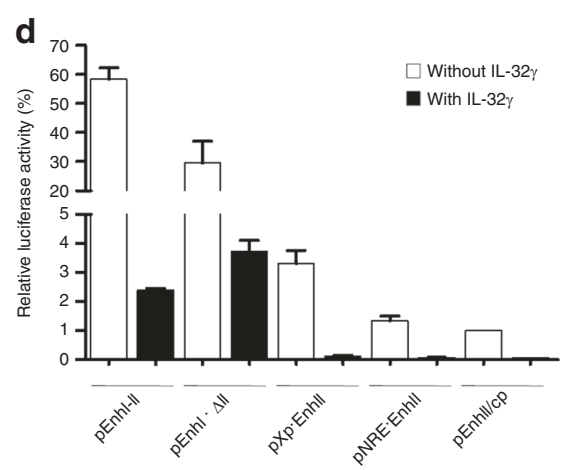
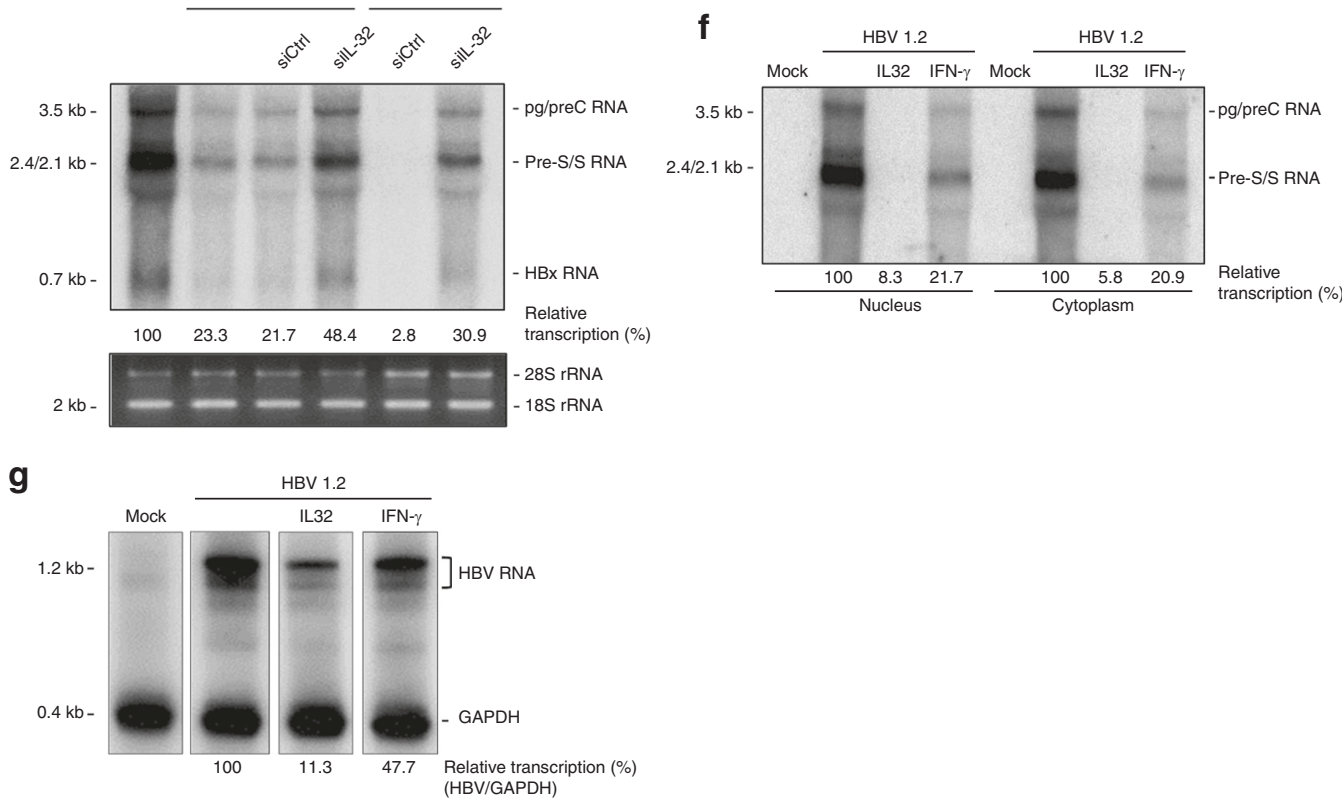

Fig. 3 IL-32 $\gamma$ suppresses HBV transcription by downregulating viral enhancer/core promoter activities. a, b At $72 \mathrm{~h}$ post-co-transfection of Huh7 cells with HBV 1.2 and IL-32 $\gamma$ vectors, the levels of HBV RNAs and proteins were determined by Northern and western blotting, respectively. The 18S RNA was used as a loading control. c Cartoon of various HBV enhancer reporter mutants used in this study. $\mathbf{d}$ Effect of IL-32 $\gamma$ on each enhancer reporter mutant in Huh7 cells. Relative luciferase activity of each enhancer clone was determined at $48 \mathrm{~h}$ post-co-transfection with either empty or IL-32 $\gamma$ vector. e HBV 1.2 and siRNAs (20 nM) were co-transfected into Huh7 cells. Next day, the cells were treated with cytokines (TNF- $\alpha$ and IFN- $\gamma$ ) in fresh medium. At $72 \mathrm{~h}$ posttransfection, the cells were harvested and the levels of HBV RNAs were determined by Northern blot analysis. $\mathbf{f}$ Huh7 cells were co-transfected with HBV 1.2 and empty or IL-32 $\gamma$ vector. Next day, the cells were treated with IFN- $\gamma$. At $72 \mathrm{~h}$ post-transfection, the cells were harvested and nuclear and cytoplasmic fractions were isolated. Total RNA was extracted and subjected to Northern blot analysis. $\mathbf{g}$ Analysis of HBV transcription rate by nuclear run-on assay using the nuclear fractions shown in $\mathbf{f}$. The level of HBV transcription was normalized to that of GAPDH RNA. Data (d) were obtained from three independent experiments (mean \pm S.D.) 
a
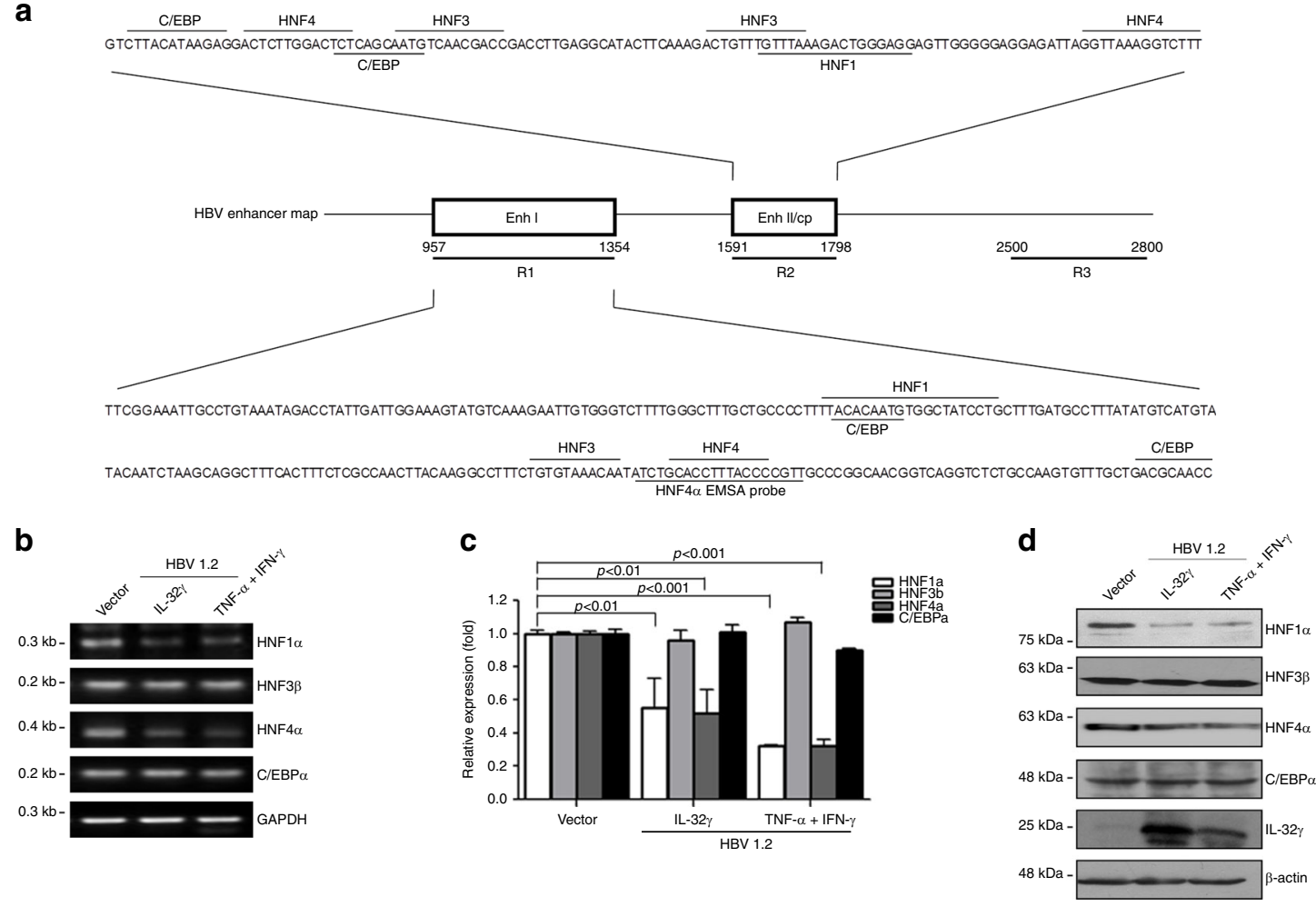

e
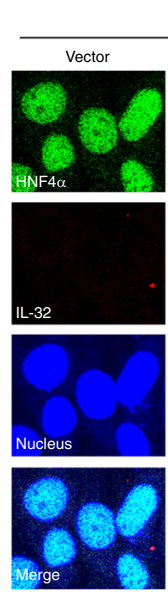

g
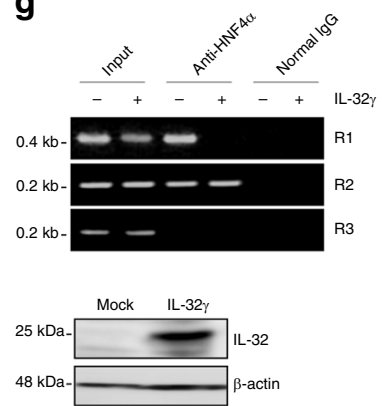

f

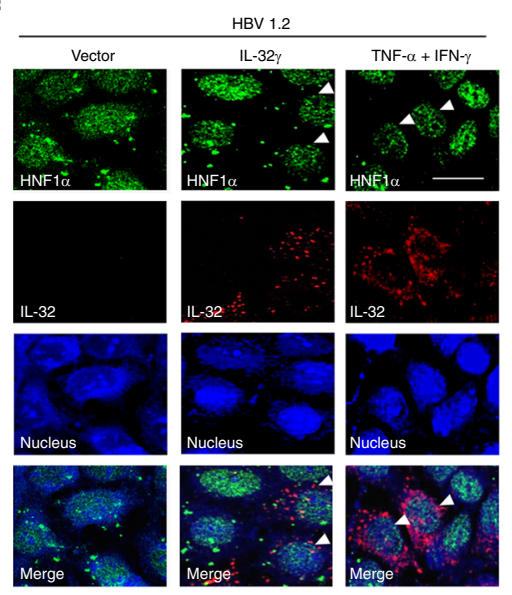

h

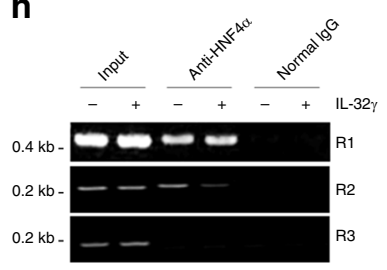

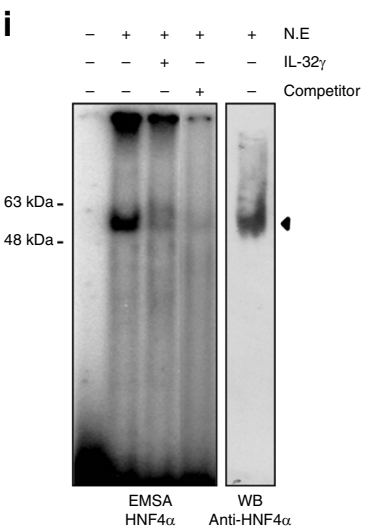

Fig. 4 IL-32 $\gamma$ downregulates HNF1 $\alpha$ and HNF4 $\alpha$ and reduces their binding to enhancers. a Map of liver-enriched transcription factor binding to HBV enhancers. b-d Huh7 cells were co-transfected with the HBV 1.2 and IL-32 $\gamma$ vectors or were treated with cytokines after HBV 1.2 transfection. The levels of transcription factors were determined by semi-quantitative RT-PCR (b), real-time PCR (c), or western blot analysis (d. e, f) Effect of IL-32 $\gamma$ and cytokines on the expression of HNF1 $\alpha$ and HNF4 $\alpha$ was analyzed by confocal fluorescence microscopy. At $24 \mathrm{~h}$ after transfection or treatment, immunofluorescence assay was performed using indicated antibodies (magnification, $\times 400$; scale bar, $50 \mu \mathrm{m}$.). $\mathbf{g}$, $\mathbf{h}$ Chromatin immunoprecipitation (ChIP) assay. Control or IL$32 \gamma$ vector was transfected into Huh7 cells and ChIP assay was performed using anti-HNF4 $\alpha$ (g) or anti-HNF1 $\alpha(\mathbf{h})$ antibody. The level of the IL-32 $\gamma$ protein was determined by western blotting. The regions for R1-R3 were shown in above diagram (a). i Electrophoretic mobility shift assay (EMSA). An aliquot of 2 $\mu \mathrm{g}$ nuclear extracts was used. A cold competitor ( 50 -fold) was used as a negative control. The protein complex was confirmed by western blotting using anti-HNF4 $\alpha$ antibody. Data (c) was obtained from three independent experiments (mean \pm S.D.). $p<0.001, p<0.01$ by Student's $t$-test 
a

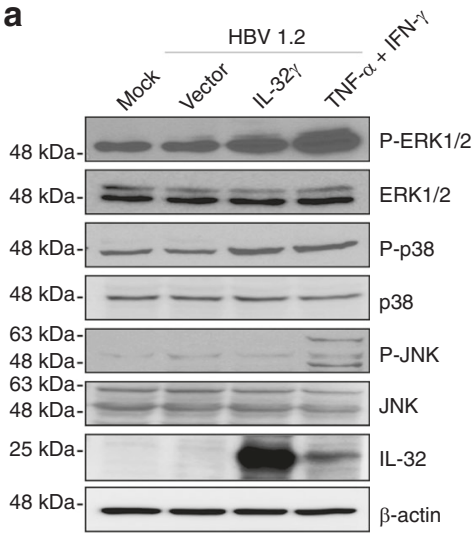

b

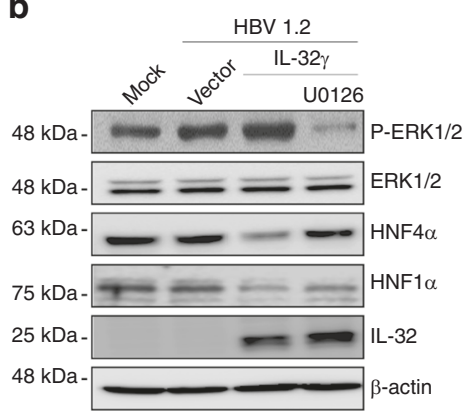

C
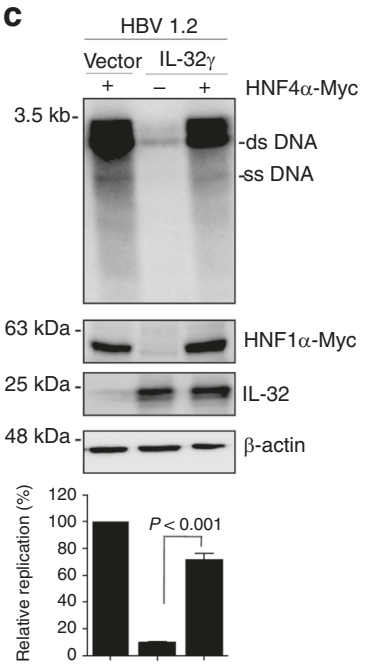

d
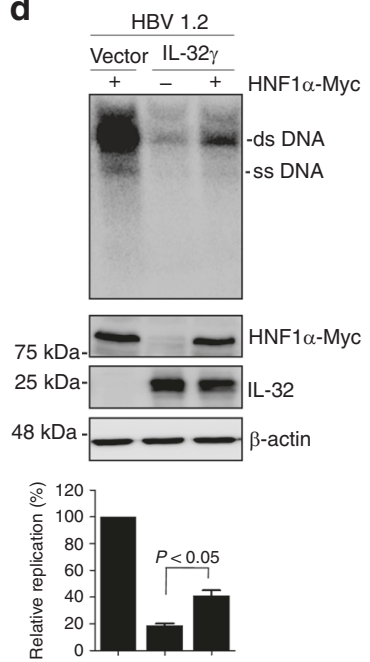

e
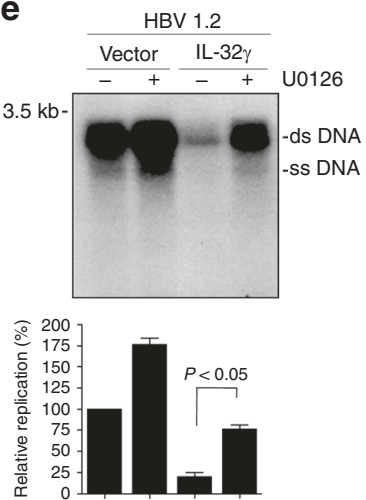

Fig. 5 Involvement of ERK1/2 signaling in IL-32 $\gamma$-mediated inhibition of HBV replication. a Effect of IL-32 $\gamma$ and cytokines on MAPK signaling in Huh7 cells. TNF- $\alpha$ and IFN- $\gamma$ were added for 30 min before harvest. Activation of MAPK signaling pathways was determined by western blotting with the indicated antibodies. $\mathbf{b}$ Effect of ERK1/2 activation inhibitor (10 $\mu \mathrm{M}$ U0126) on the expression of HNFs. c-e Effect of HNF4 $\alpha$ (c), HNF1 $\alpha$ (d), and U0126 (e) on IL-32 $\gamma$ mediated inhibition of HBV replication. Viral replication and protein expression were determined by Southern and western blot analyses, respectively. U0126 was added for $48 \mathrm{~h}$ at a final concentration of $10 \mu \mathrm{M}$. Data (c-e) were obtained from three independent experiments (mean \pm S.D.). $p<0.001, p<$ 0.05 by Student's $t$-test

main cause of IL-32 $\gamma$-mediated inhibition of HBV transcription and replication.

IL-32 $\gamma$ suppresses $\mathrm{HBV}$ in a mouse model. To investigate whether IL-32 $\gamma$ suppresses HBV in vivo, we established an HBV mouse model by using a hydrodynamic injection method ${ }^{37,38}$. After hydrodynamic injection of a plasmid carrying replicationcompetent HBV (HBV 1.2) and a plasmid for IL-32 $\gamma$ expression into the tail vein, mouse liver tissues and sera were analyzed. Expression of IL-32 $\gamma$ effectively suppressed both HBV replication in the liver and HBsAg secretion into serum (Fig. 6a, b). Immunohistochemical analysis showed that the expression of the $\mathrm{HBV}$ core protein was also significantly decreased in the liver (Fig. 6c).

As we showed that IL-32-mediated inhibition of HBV replication is an intracellular event, if there is no paracrine effect, the IL-32 and HBV plasmids transduced by hydrodynamic injection should be mostly co-localized in same hepatocytes. To check this, we transduced a mixture of RFP and GFP plasmids (1:1) into mouse liver and analyzed whether the two proteins are co-expressed in the same hepatocytes (Fig. 6d). Indeed, RFP and GFP were co-expressed in most of the transduced hepatocytes. Our observation is consistent with the previous reports that the two plasmids delivered by hydrodynamic injection were colocalized in $91 \%$ of hepatocytes examined ${ }^{39,40}$.

In addition, when a mixture of $\mathrm{HBV}$ and $\beta$-gal plasmids (with or without IL-32 $\gamma$ ) was hydrodynamically injected into mouse liver, immunofluorescence analysis showed that the HBV core protein and $\beta$-gal were co-localized in most of the transduced hepatocytes (Fig. 6c). Although the expression of the core protein was suppressed by IL-32, it seems evident that two proteins were co-localized in same hepatocytes. These results indicate that IL$32 \gamma$ strongly suppresses HBV in vivo and the IL-32-mediated inhibition of $\mathrm{HBV}$ in mouse liver is due to the co-expression of IL-32 and HBV in the same hepatocytes, not to the paracrine effect of IL-32.

Cytokine-induced IL-32 $\gamma$ suppresses HBV in PHHs. Finally, to verify the physiological relevance of our findings, we validated the above results using $\mathrm{PHH}$ infected with HBV. To determine the optimal HBV infection levels, $\mathrm{PHHs}$ were incubated with $\mathrm{HBV}$ inoculum (100-2000 HBV Geq per cell) and the expression levels of the surface (HBsAg) and core ( $\mathrm{HBcAg}$ ) antigens were analyzed at 9 days post-infection (dpi). As shown in Supplementary Figure $10, \sim 80 \%$ of $\mathrm{PHH}$ were infected at $1000 \mathrm{HBV}$ Geq per cell; thus, this condition was used for further studies. 
a

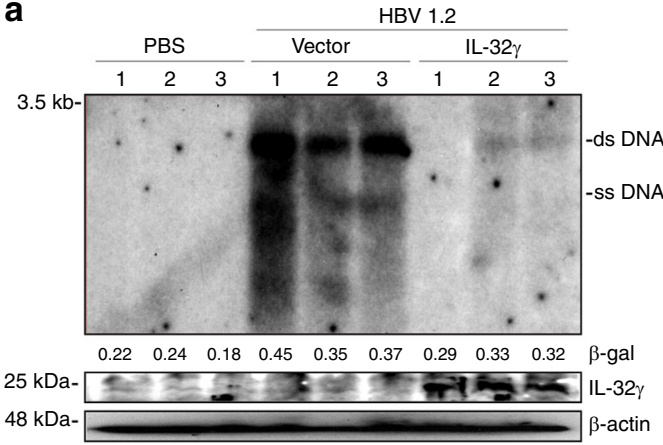

b

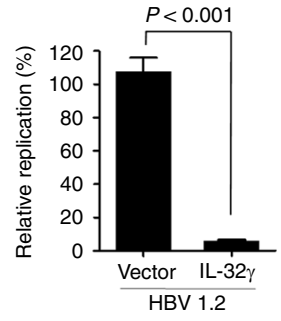

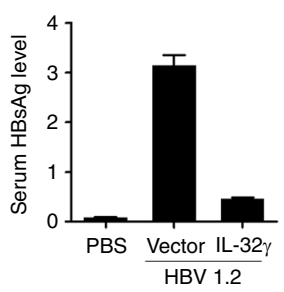

C

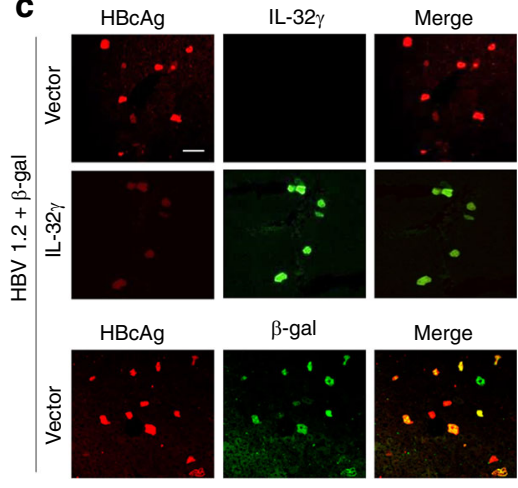

d

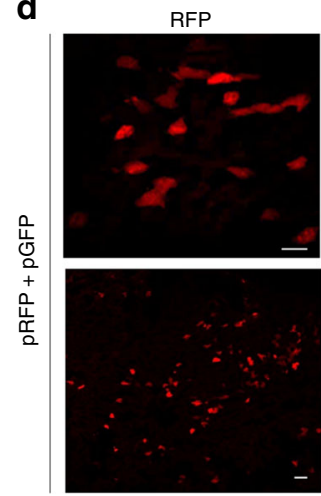

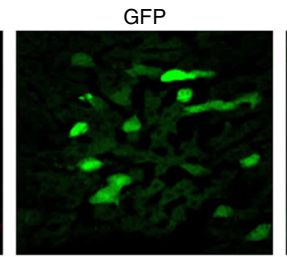

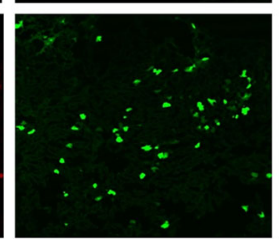

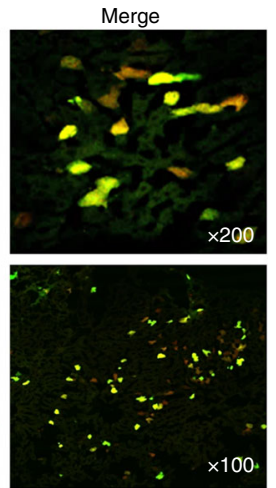

Fig. 6 IL-32 $\gamma$ suppresses HBV in a mouse model. a Six-week-old male mice (3 mice per group) were killed 4 days after hydrodynamic injection of the indicated plasmids: control vector, $20 \mu \mathrm{g}$; HBV 1.2, $20 \mu \mathrm{g}$; $\beta$-gal, $5 \mu \mathrm{g}$. HBV replication was analyzed by Southern blotting using 50 mg of liver tissues. The level of IL-32 $\gamma$ and $\beta$-actin were analyzed by western blotting. b The level of secreted HBsAg in serum was measured by ELISA. c Immunofluorescence analysis of the HBV core, $\beta$-gal, and IL-32 $\gamma$ proteins in mouse liver tissues prepared as in $\mathbf{a}$. $\beta$-gal protein staining was used as a control for hydrodynamic injection. Magnification, $\times 200$; scale bar, $50 \mu \mathrm{m}$. d Immunofluorescence analysis of the co-expression of RFP and GFP proteins in the same hepatocytes. Each plasmid (pEF1 $\alpha$-RFP and pEF1 $\alpha$-GFP; $10 \mu \mathrm{g}$ ) was hydrodynamically injected into mouse liver. Sections were prepared with a tissue cryotome. Green and red fluorescence signals were observed with an inverted fluorescence microscope at indicated magnification (scale bar, $50 \mu \mathrm{m})$. Data (a, b) were obtained from three independent experiments (mean \pm S.D.). $p<0.001$ by Student's $t$-test

To assess the involvement of IL-32 $\gamma$ in TNF- $\alpha$-mediated and IFN- $\gamma$-mediated suppression of HBV, we designed the experimental scheme described in Fig. 7a. At 4 dpi, the detection of similar levels of secreted HBeAg demonstrated that the level of $\mathrm{HBV}$ infection in each well was similar (Fig. 7a, bottom). At 6 dpi, IL-32 was knocked down by infection with shIL-32 lentivirus and the cells were treated with cytokines as described in Fig. 7a. First, we compared the induction level of IL-32 $\gamma$ by TNF- $\alpha$ or IFN- $\gamma$ between Huh7 cells and PHHs. Importantly, PHHs produced a much higher level of IL-32 $\gamma$ ( 55 -fold) than did Huh7 cells both under unstimulated and cytokine-stimulated conditions (Supplementary Fig. 11). Suppression of HBV by cytokines in PHHs was confirmed by reduced HBsAg secretion (Supplementary Fig. 11).

To efficiently knockdown the expression of IL-32 $\gamma$ in PHHs, we infected Huh7 cells with four different shIL-32 lentiviruses and selected two lentiviral clones, sh32(2) (less effective) and sh32 (4) (most effective) for further study (Supplementary Fig. 12). The effect of sh32(4) lentivirus was confirmed by the rescue of the cytokine-mediated suppression of HBV replication in HepG2 cells (Supplementary Fig. 13).

The knockdown of cytokine-induced IL-32 $\gamma$ completely restored the expression levels of HNF1a and HNF4a in PHHs (Fig. 7b). Using the same batch of cell lysates, we quantified HBV replication by real-time PCR (Fig. 7c). Importantly, IL-32 $\gamma$ knockdown remarkably rescued the TNF- $\alpha$-mediated and IFN- $\gamma$ mediated inhibition of $\mathrm{HBV}$ replication and $\mathrm{HBeAg}$ expression (Fig. $7 c, d$ ). Under these experimental conditions, the overall levels of HNF1a and HNF4a were correlated with the levels of
HBV replication and secreted $\mathrm{HBeAg}$. These results demonstrate that IL-32 $\gamma$ mediates the anti-HBV activity of TNF- $\alpha$ and IFN- $\gamma$ in PHHs. Collectively, our data indicate that IL-32 $\gamma$ has a significant role in cytokine-mediated suppression of $\mathrm{HBV}$ during the natural course of $\mathrm{HBV}$ infection.

\section{Discussion}

In the present study, we demonstrated a novel function of IL-32 $\gamma$ in hepatocytes, where it acts as a non-cytokine-like molecule: it mediates the anti-HBV activity of TNF- $\alpha$ and IFN- $\gamma$ intracellularly. Based on our results, we propose a model of cytokinemediated suppression of HBV (Fig. 7e). When hepatocytes are infected with $\mathrm{HBV}$, the nearby hepatic immune cells secrete TNF$\alpha$ and IFN- $\gamma$ to suppress $\mathrm{HBV}$ in a non-cytopathic manner ${ }^{4}$. These cytokines synergistically induce the expression of IL-32 $\gamma$, which in turn downregulates the expression of HNF1a and $\mathrm{HNF} 4 a$, the transcription factors essential for HBV transcription, through the ERK1/2 pathway. Our findings may provide a mechanism of cytokine-mediated non-cytopathic viral clearance.

Generally, cytokines are crucial in host defense against pathogens and are released from immune cells and affect the same or nearby cells through autocrine or paracrine pathways. IL32 was also identified as a cytokine secreted from NK cells ${ }^{12,13}$. Unexpectedly, we found that IL-32 $\gamma$ was not secreted at all not only in liver cell lines but also in $\mathrm{PHH}$ and differentiated HepaRG cells when it was expressed by either transfection or induction by cytokines (Figs. 1f, g, and 2b), and strongly 

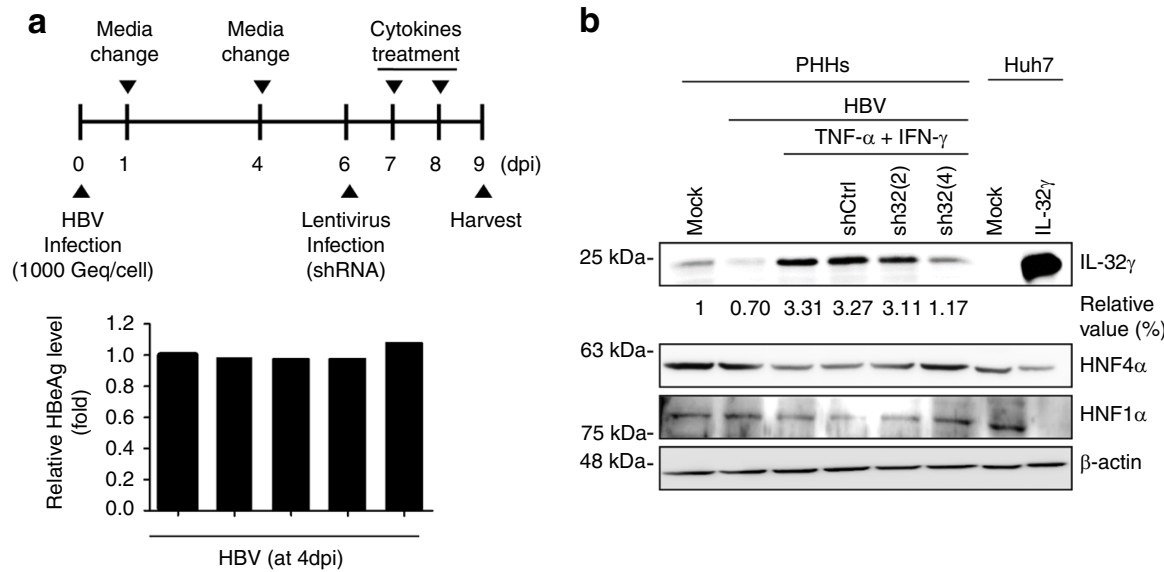

C

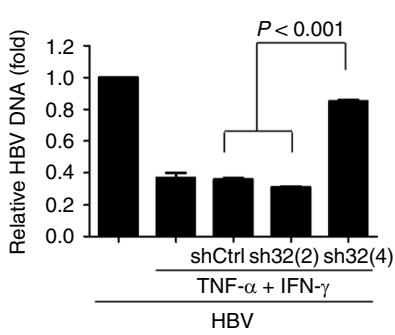

d

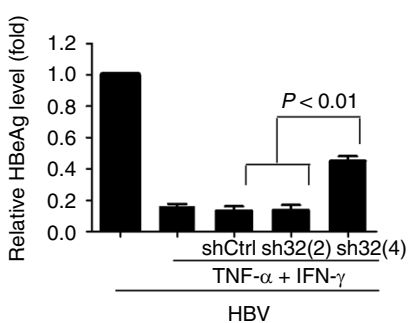

e

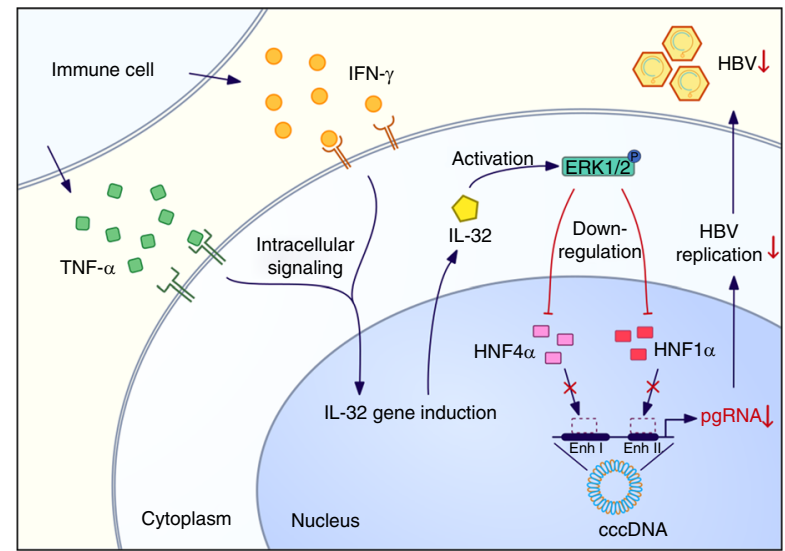

Fig. 7 IL-32 $\gamma$ is involved in cytokine-mediated suppression of HBV in PHHs. a The experimental scheme. PHHs were infected with 1000 genome equivalents HBV per cell. At 4 days post-infection (dpi), the HBeAg level was determined by ELISA. $\mathbf{b}$ Effect of IL-32 knockdown on cytokine-induced downregulation of HNF1 $\alpha$ and HNF $4 \alpha$. PHHs were infected with HBV and shIL-32 lentivirus as described in a. Cytokines were added for 2 days before harvest. c, $\mathbf{d}$ Effect of IL-32 knockdown on cytokine-induced inhibition of HBV replication and HBeAg secretion. Aliquots of cell lysates were used for realtime PCR and HBeAg ELISA. e A hypothetical model of IL-32 $\gamma$-mediated suppression of HBV through downregulation of HNF1 $\alpha$ and HNF4 $\alpha$ expression. When hepatocytes are infected with HBV, immune cells secrete TNF- $\alpha$ and IFN- $\gamma$, which induce the expression of IL-32 $\gamma$. IL-32 $\gamma$ activates ERK1/2, which in turn downregulates the expression of HNF1 $\alpha$ and HNF4 $\alpha$. Finally, the binding of HNFs to the viral enhancers/core promoter is reduced, which consequently inhibits HBV transcription and replication. Data $(\mathbf{c}, \mathbf{d})$ were obtained from three independent experiments (mean \pm S.D.). $p<0.001$ by Student's $t$-test

suppressed HBV replication. These data demonstrate that IL-32 $\gamma$ functions through a cytoplasmic event, not a paracrine or autocrine pathway, suggesting that IL-32 $\gamma$ functions as a noncytokine-like molecule in $\mathrm{HBV}$ suppression, at least in hepatocytes.

Enormous efforts have been dedicated to the identification of the receptor for IL-32; however, to date, the identity of this receptor is still unclear. In our study, extracellular treatment with active rhIL-32 $\gamma$ had no effect on HBV, whereas ectopic or cytokine-induced expression of IL-32 $\gamma$ strongly suppressed HBV replication (Figs. 1 and 2). As the cytokine-mediated anti-HBV activity of IL-32 occurs entirely in the cytoplasm, our finding suggests that the IL-32 receptor is not necessary to mediate cytokine-induced viral suppression in hepatocytes.

Six alternative splice variants of IL-32 mRNA have been identified; among them, IL-32 $\gamma$ is the most active form in terms of inducing proinflammatory cytokines ${ }^{15}$. IL-32 $\alpha, \beta$, and $\gamma$ share common exons. The difference in the amino acid sequence between them is in the short N-terminal and C-terminal regions (Fig. 2c). In this study, intracellular expression of any of the three representative IL-32 isoforms (IL-32 $\alpha$, IL-32 $\beta$, and IL-32 $\gamma$ ) suppressed the replication of $\mathrm{HBV}$, with the order of the antiviral activity: IL-32 $\gamma>$ IL-32 $\beta>$ IL-32 $\alpha$ (Fig. $2 d$ ). These data suggest that the additional C-terminal and N-terminal domains in IL-32 $\gamma$ 
are responsible for strong anti-HBV activity. However, ectopically expressed IL-32 $\gamma$ did not induce the representative proinflammatory cytokines (TNF- $\alpha$, TGF- $\beta$, IL- $1 \beta$, IL-6, IFN- $\alpha$, IFN- $\beta$, and IFN- $\gamma$ ) in hepatocytes (Supplementary Fig. 6b). These results suggest that IL-32 $\gamma$ activity in cytokine induction is totally different from that in the antiviral response. Nevertheless, it is notable that IL-32 $\gamma$ is the most active form both in the induction of proinflammatory cytokines and antiviral activity. Deciphering why IL-32 $\gamma$ is the most active form may provide a clue to its behavior as a cytokine and a non-cytokine-like molecule.

Several cytokines inhibit $\mathrm{HBV}$ replication through diverse mechanisms; ${ }^{4,5}$ Among them, TNF- $\alpha$ and IFN- $\gamma$ are secreted mainly by $\mathrm{T}$ cells and suppress $\mathrm{HBV}$ in a non-cytolytic manner ${ }^{1,3,8}$. TNF- $\alpha$ inhibits HBV RNA production and decreases capsid stability $^{1-3,6}$. We also showed that p22-FLIP mediates the suppression of $\mathrm{HBV}$ by TNF- $\alpha^{10}$. IFN- $\gamma$ reduces the pregenomic RNA-containing capsids ${ }^{5}$. Hepatocystin augments the IFN- $\gamma$ mediated suppression of $\mathrm{HBV}^{11}$. Several cytokine-induced antiviral proteins such as ISGs, OAS, MX, and CIAP2 are involved in TNF- $\alpha$-induced or IFN- $\gamma$-induced inhibition of HBV; ${ }^{41-43}$ however, these antiviral proteins seemed not to be related to the antiHBV activity of IL-32 $\gamma$ (Supplementary Fig. 6a). Importantly, TNF- $\alpha$ and IFN- $\gamma$ have been reported to reduce the levels of HBV cccDNA in hepatocytes ${ }^{9}$. In this study, we showed that IL-32 $\gamma$ is strongly induced by both TNF- $\alpha$ and IFN- $\gamma$ in hepatocytes and mediates the inhibition of HBV by these cytokines by downregulating HNFs (Figs. 1 and 7).

It is well established that cytokines inhibit $\mathrm{HBV}$ at the posttranscriptional level in a mouse model ${ }^{30}$. The stability of HBV RNA is reduced by cytokine-induced depletion of the RNA stabilizing La protein ${ }^{31-33}$ or destabilization of HBV RNAcontaining capsids via proteasome $e^{44,45}$ or kinase activity ${ }^{46}$. Therefore, we carefully examined whether there is any difference between mouse and human hepatocytes in terms of the cytokine effect on HBV suppression. As shown in Supplementary Figures 7, 8, and 9, cytokines appear to suppress HBV RNAs through a La-dependent pathway in mouse hepatocytes but through a Laindependent pathway in human hepatocytes. There was no restoration of IL-32-mediated downregulation of HBV RNA or antigens when we treated Huh7 cells with the same inhibitors of JAK (AG490) and proteasome (MG132) that were used in previous studies (Supplementary Fig. 14). These results demonstrate that the antiviral effect of IL-32 is independent of proteasome or kinase activity at least in human hepatocytes. Altogether, our results suggest that cytokines suppress $\mathrm{HBV}$ at the posttranscriptional level in mouse hepatocytes, mainly through a La-dependent pathway; however, they suppress $\mathrm{HBV}$ at the transcriptional level in human hepatocytes through an IL-32dependent pathway.

Importantly, intensive searching with sequences of all IL-32 isoforms did not reveal a homologous mouse gene ${ }^{12}$; therefore, studying the role for endogenous IL-32 in mice is not possible. To confirm the absence of IL-32 in mice, we isolated PMHs and confirmed that IL-32 is not detectable in these cells upon cytokine induction (Supplementary Fig. 7d). The difference in the mechanism involved in cytokine-mediated suppression of $\mathrm{HBV}$ between human and mouse is probably due to the fact that the mouse does not have any IL-32 homologs and does not support HBV infection.

During acute $\mathrm{HBV}$ infection, the non-cytopathic viral clearance of HBV is mediated by TNF- $\alpha$ and IFN- $\gamma$ secreted mainly by $\mathrm{T}$ cells and is achieved through the inhibition of viral transcription and replication ${ }^{1}$ or reduction of $\mathrm{HBV}$ cccDNA through the induction of $\mathrm{APOBEC}^{9}$. We found no morphological or biochemical evidence that either treatment with TNF- $\alpha$ and IFN- $\gamma$ or overexpression of IL-32 $\gamma$ induced cell damage or death (Figs. 1 and 2). Moreover, the mouse liver tissues overexpressing IL-32 $\gamma$, which resulted in $\mathrm{HBV}$ suppression, were intact, without any histological signs of tissue damage (Fig. 6c), suggesting that HBV was suppressed through a non-cytolytic pathway. These findings may provide a mechanism of non-cytopathic viral clearance by cytokines or the induction of IL-32 $\gamma$ may contribute to the noncytopathic clearance of HBV.

It is worth noting that the basal level of IL-32 $\gamma$ is much higher in PHHs ( 55-fold) than in Huh7 cell (Supplementary Fig. 11). Moreover, IL-32 $\gamma$ is highly induced by TNF- $\alpha$ or IFN- $\gamma$ treatment in PHHs. These observations support the possibility that IL-32 $\gamma$ has an important role during acute HBV infection and is involved in cytokine-mediated suppression of $\mathrm{HBV}$ during the natural course of HBV infection.

TNF- $\alpha$ is induced from human hepatocytes in chronic viral hepatitis ${ }^{47}$ and the levels of TNF- $\alpha$ and IFN- $\gamma$ in serum of acute hepatitis B patients are higher than in healthy controls ${ }^{9}$. Together with these reports, the observation that the expression level of IL$32 \gamma$ in chronic HBV-infected liver was increased ${ }^{48}$ may emphasize the clinical relevance of our finding that IL-32 is induced by TNF- $\alpha$ and IFN- $\gamma$ in infected hepatocytes.

Single nucleotide polymorphisms in the promoters of TNF- $\alpha$ and IFN- $\gamma$ genes affect the expression of these cytokines and are associated with HBV clearance ${ }^{49,50}$. As IL-32 $\gamma$ was induced by treatment with TNF- $\alpha$ and IFN- $\gamma$ (Figs. 1 and 7), promoter polymorphisms in TNF- $\alpha$ and IFN- $\gamma$ may correlate with the expression level of intrahepatic IL-32 $\gamma$, which may contribute to HBV clearance.

As the TNF- $\alpha$-induced activation of NF- $\kappa B$ signaling ${ }^{51}$ and the nitric oxide pathway inhibit HBV replication ${ }^{52}$, we tested whether TNF- $\alpha$-induced IL-32 $\gamma$ inhibits HBV replication through these pathways. Neither activation of NF- $\kappa \mathrm{B}$ nor production of nitric oxide appeared to be involved in IL-32 $\gamma$-mediated inhibition of HBV (Supplementary Fig. 15). Nevertheless, our data showed that IL-32 $\gamma$ activates ERK1/2 signaling and controls HNF expression. These data are consistent with the previous studies that HNFs are regulated by the MAPK signaling pathway 26,36 .

Previously, Li et al. ${ }^{23}$ showed that IL-32 has no antiviral effect in HepG2.2.15, Huh7, L02, and Hep3B cells. However, our data clearly show that IL-32 inhibits HBV replication in HepG2, Huh7, L02, and Hep3B cells (Supplementary Fig. 3). Interestingly, similar to their study, IL-32 showed no antiviral effect in HepG2.2.15 and HepAD38 cells where HBV was stably expressed. However, HBV enhancer activity was commonly reduced in both cell lines when they were transfected with an enhancer reporter (Supplementary Fig. 16). A similar difference in the effect of IFN on HBV transcription was observed between HepG2 and HepDE19 stable cell lines ${ }^{29}$. The expression of CMV promoterdriven GFP which was transfected as a control was not affected by IL-32 (Fig. 2a and Supplementary Fig. 3a). These results suggest that IL-32 specifically suppresses viral enhancers/promoters when the HBV genome is present in an episomal form, reminiscent of HBV cccDNA.

Although IL-32 $\gamma$ downregulated both HNF1a and HNF4a, supplementation with HNF1a had only a very small effect on HBV replication, whereas HNF4a almost completely restored it (Fig. 5c, d). These results suggest that the reduced expression of HNF4 $\alpha$ has a major role in IL-32 $\gamma$-mediated inhibition of $\mathrm{HBV}$ replication. This is probably because HNF4a is the master transcription factor in $\mathrm{HBV}$ replication ${ }^{24,25}$ and partly because HNF4a is necessary for HNF1a production ${ }^{53}$. Interestingly, although the binding sites for HNF1 $\alpha$ and HNF4a are present both in the EnhI and EnhII regions, IL-32 $\gamma$ specifically reduced the HNF4a binding to EnhI and HNF1a binding to EnhII/Cp (Fig. $4 \mathrm{~g}, \mathrm{~h}$ ). As the promoter activity of EnhI is much higher than that of EnhII/Cp ( $\sim 30$ fold) (Fig. 3d) and HNF4a is the master 
regulator of HBV replication, the specific reduction in HNF4a binding to EnhI by IL-32 $\gamma$ (Fig. $4 \mathrm{~g}$ ) seems to be the optimal strategy for the host to maximize the anti-HBV activity of IL-32 $\gamma$. How IL-32 $\gamma$ alters the binding of HNFs to specific enhancers needs further investigation.

IL-32 $\gamma$ does not appear to regulate the common antiviral genes or transcription factors, which have a critical role in replication of several viruses. IL-32 $\gamma$ suppresses the replication of $\mathrm{VSV}^{16,17}$, HIV-1 ${ }^{18,19}$, and influenza virus ${ }^{20-22}$ through an extracellular pathway. Although IL-32 is known to suppress influenza virus in lung cells ${ }^{20-22}$, it showed no effect on its replication in hepatocytes (Fig. $2 \mathrm{f}$ and Supplementary Fig. 5). It activates the expression of several cytokines such as IL-6, TNF- $\alpha$, and IFN- $\gamma$ in immune cells and inhibits HIV-1 ${ }^{18}$. However, these cytokines were not induced by IL-32 $\gamma$ in hepatocytes (Supplementary Fig. 6b). Although IL-32 is involved in hepatitis C virus (HCV)related liver inflammation and fibrosis, it shows no inhibitory effect on the replication of HCV, another hepatotropic virus ${ }^{54}$. Taken together, the available data indicate that the antiviral activity of IL-32 is cell-specific and target virus-specific.

In summary, in this study we showed that intracellular IL-32 $\gamma$ mediates the anti-HBV activity of TNF- $\alpha$ and IFN- $\gamma$ by reducing the expression of HNFs. Thus, IL-32 $\gamma$ directly suppresses HBV at the transcriptional level through a non-cytokine-like function in hepatocytes. Our finding may provide a mechanism of noncytopathic viral clearance and could be useful for developing new therapeutic options for the control of hepatitis B.

\section{Methods}

Cell culture and transfection. Human hepatoma cell lines (Huh7, Korean Cell Line Bank, KCLB, 60104; HepG2, American Type Culture Collection, ATCC, HB8065; Hep3B, American Type Culture Collection, ATCC, HB-8064) and normal hepatocyte cell LO2 (The Cell Bank of Type Culture Collection of Chinese Academy of Sciences, CBTCCCAS) were grown in Dulbecco's modified Eagle's medium (DMEM) (Gibco BRL, Grand Island, USA) supplemented with 10\% (v/v) heat-inactivated fetal bovine serum (Gibco BRL), 1\% penicillin, and $1 \%$ streptomycin (Gibco BRL) at $37^{\circ} \mathrm{C}$ in $5 \% \mathrm{CO}_{2}$ incubator Transient transfection of cell lines was performed at $70-80 \%$ confluency using Lipofectamine 2000 reagent (Invitrogen, Carlsbad, CA, USA) according to the manufacturer's instructions. Differentiated HepaRG cells (Biopredic, Saint-Gregoire, France) were maintained according to the supplier's protocol.

\begin{abstract}
Isolation of primary hepatocytes and transfection. Primary mouse hepatocytes (PMHs) were isolated from mouse liver by using a two-step collagenase perfusion method $^{55}$. The liver specimens $(\sim 0.5 \mathrm{~cm} \times 0.5 \mathrm{~cm})$ were perfused through vein vessels on the cut surface of the specimen with cold perfusion buffer supplemented with collagenase $(0.5 \mathrm{~g} / \mathrm{L})$ and calcium chloride $(0.56 \mathrm{~g} / \mathrm{L})$. The cells were filtered through stainless steel meshes in two steps (grid size, 300 and $150 \mu \mathrm{m}$ ). The cells were washed twice with cold William's medium ${ }^{10,28}$. Human liver tissue specimens proved negative for HBV and HCV infection were obtained from therapeutic hepatectomies. Informed consent was obtained from patients before the procedure. PHHs were isolated with the approval from the Institutional Review Boards at St. Mary's Hospital (IRB No. UC14TIS10131) and Korea University Hospital (IRB No. ED10287). For transient transfection of PMHs and PHHs, JetPEI Hepatocyte reagent (Polyplus, Salt Lake City, NY, USA) was used according to the manufacturer's protocols.
\end{abstract}

Plasmid construction. The plasmids for HBV $1.2^{56}, \mathrm{NF}-\mathrm{kB}-\mathrm{luc}{ }^{57}$, and HBV enhancer-luciferase reporters ${ }^{10}$ were used in our previous reports. The plasmids for pCAGGS control, IL-32 $\alpha$, IL-32 $\beta^{58}$, and IL-32 $\gamma^{59}$ (GenBank no: BC009401) were also described previously. The expression plasmids for pHNF4a-Myc and pHNF1 $\alpha-M y c$ were constructed by PCR amplification with a HepG2 cDNA library as a template and subcloned into the $\mathrm{pCMV}-\mathrm{Myc}$ vector (Clontech, Mountain View, CA, USA).

Cell viability assay. Cell viability was determined by using a viability assay kit (Welgene, Seoul, Korea). After transfection or treatment of cells, the culture media were transferred to 96-well plates. The XTT and PMS reagents were added and incubated for $1 \mathrm{~h}$. Cell viability was determined using a spectrophotometer as absorbance at $450 \mathrm{~nm}$.
RNA interference. The IL-32 siRNA was synthesized by ST Pharm (Seoul, Korea) as the sense ( $5^{\prime}$-GGCUUAUUAUGAGGAGCAGTT-3') and antisense oligonucleotides ( $5^{\prime}$-CUGCUCCUCAUAAUAAGCCTT-3'). Knockdown of IL-32 was confirmed by western blot analysis (Supplementary Fig. 1). The SSB/La siRNA was purchased from Santa Cruz Biotechnology (sc-40915). The siRNAs were transfected into cells by using Lipofectamine 2000 (Invitrogen). A set of Sigma Mission shRNA lentiviral constructs (TRCN0000174112, TRCN0000372658,

TRCN0000059216, and TRCN0000372720) and control shRNA (pGL2 plasmid) were used for IL-32 knockdown in the presence of the packaging plasmids VSV-G and delta 8.2. All shRNA vectors for IL-32 were confirmed by sequencing. Vectors for shRNAs, delta 8.2, and VSV-G were co-transfected into $293 \mathrm{~T}$ cells with Lipofectamine 2000. Culture supernatants were collected $24 \mathrm{~h}$ after transfection and used to infect Huh7, HepG2, and PHH cells in the presence of $6 \mu \mathrm{g} / \mathrm{mL}$ polybrene for $12 \mathrm{~h}$ at $37^{\circ} \mathrm{C}$.

Western blot analysis. Western blot analysis was performed as follows ${ }^{60}$. Cells were harvested 2 or 3 days after transfection with indicated plasmids, and lysed by RIPA buffer [ $20 \mathrm{mM}$ Tris/HCl, $1 \%$ NP-40, 0.5\% protease inhibitor cocktail (Sigma, St. Louis, MO), $150 \mathrm{mM} \mathrm{NaCl}, 2 \mathrm{mM} \mathrm{KCl}, \mathrm{pH} 7.4]$. After spin-down cell debris, the lysates were separated by SDS-PAGE and transferred to PVDF membrane. Primary antibodies against the following proteins and epitopes were used: HBV core protein (Dako, B0586, Hamburg, CA, USA, 1:2000), GFP (Sigma, G6795, 1:2000), HBsAg (Abcam, ab9193, Cambridge, UK, or Dako, 1:2000), HNF1a (Santa Cruz Biotechnology, sc-8986, 1:2000), HNF3 $\beta$ (Santa Cruz Biotechnology, sc-101060, 1:2000), CEBPa (Santa Cruz Biotechnology, sc-9314, 1:2000), HNF4a (Santa Cruz Biotechnology, sc-6556, 1:2000), Myc (Abcam, ab39688, 1:2000), lamin (Santa Cruz Biotechnology, sc-376248, 1:2000), NP (AbD Serotec, Raleigh, NC, USA, 1:2000), ICP27 (Abcam, 1:2000), tubulin (Santa Cruz Biotechnology, sc-8035, 1:2000), and actin (Sigma, A5316, 1:5000). Reagents used in the present study included recombinant human IL-32 $\gamma$ (rhIL-32 $\gamma$ ) (YbdY, Seoul, Korea), anti-IL-32 antibody (YbdY, PAB101, 1:2000), anti-SSb/La antibody (Santa Cruz Biotechnology, Dallas, TX, USA, sc-80656, 1:2000), human TNF- $\alpha$ (YbdY), human IFN- $\gamma$ (LG, Jeonbuk, Korea), mouse TNF- $\alpha$ (mTNF-a) (Peprotech, Rocky Hill, NJ, USA, 315-01A), mouse IFN- $\gamma$ (mIFN- $\gamma$ ) (Peprotech, 315-05), U0126 (Cell Signaling, Boston, New York, USA), AG490 (Sigma, St. Louis, MO, USA), and MG132 (Merck Millipore, MA, USA). Primary antibodies were used at 1:2000 dilution. Goat anti-mouse immunoglobulin $\mathrm{G}$ conjugated with horseradish peroxide (secondary antibody; Santa Cruz Biotechnology) was used; signals were detected by using the ECL Plus reagent (ELPIS, Taejeon, Korea), except that HNF1a was detected with the Femto Substrate (Thermo, Rockford, IL, USA). The same membranes were stripped and re-blotted to detect the levels of other proteins. The original uncropped figures can be found in the supplementary information (Supplementary Fig. 17-38).

Luciferase reporter analysis. The luciferase reporter plasmids harboring deletion mutants of $\mathrm{HBV}$ enhancer regions were constructed and activities of these reporters were determined as follows ${ }^{10}$. Approximately $2 \times 10^{5}$ cells cultured on 12 -well plate were transfected with a plasmid mixture containing $0.5 \mu \mathrm{g}$ enhancer-luciferase (pEnhI.II, pEnhI. $\Delta$ II, pXp.EnhII, pNRE.EnhII, or pEnhII/cp), $0.5 \mu \mathrm{g}$ IL-32 $\gamma$, and $0.25 \mu \mathrm{g} \beta$-gal. Control vector (pCAGGS) was used to normalize the amount of transfected DNA. After $48 \mathrm{~h}$ post-transfection, cells were harvested and subjected to measure luciferase activity using the Steady Glo-Luciferase system (Promega, Madison, WI). Data were obtained from at least three independent experiments.

ELISA. The expression level of IL-32 was measured with an IL-32 ELISA kit (YbdY). A total of $5 \times 10^{5}$ cells were seeded per well of a 12-well plate. After $48 \mathrm{~h}$ post-treatment with cytokines or transfection, cells were harvested, and 1/10 of culture medium or lysate of each group was used for ELISA. The final data were converted to the total amount of IL-32 per well of a 12-well plate. The expression levels of HBeAg and HBsAg were measured using an HBeAg/HBsAg ELISA kit (Wantai Pharm Inc., Beijing, China) according to the manufacturer's instructions. Data were obtained from at least three independent experiments.

Infection with HBV, HSV, and IAV. HBV infection was carried out as follows ${ }^{10,28,57}$. PHHs or differentiated HepaRG cells were infected with $1000 \mathrm{HBV}$ genome equivalents per cell (Geq/cell) in fresh medium containing $4 \%$ PEG and $2.5 \%$ DMSO. At $15 \mathrm{~h}$ post-infection, the medium was replaced with fresh medium and the cells were harvested 9 days post-infection.

HSV-1 K26GFP, a recombinant herpes simplex type 1 expressing GFP (HSV1_GFP) was obtained from Dr. Prashant Desai (Johns Hopkins University) ${ }^{61}$. The virus titer was determined by plaque assays with Vero cells overlaid with $1 \%$ methylcellulose (Sigma) in normal growth medium. At 3 days after infection, the cells were fixed and stained with $2 \%$ crystal violet (Merck Millipore) in 20\% ethanol.

The influenza A virus H1N1 strain (A/WSN/33) eight-plasmid reverse-genetics system was kindly provided by Dr. Ren Sun ${ }^{62}$. A/WSN/33 expressing GFP (A/WSN/ 33_GFP) was generated with this supplemented with an enhanced GFP plasmid as previously described ${ }^{63}$. The virus titer was determined by TCID50 assay with MDCK cells according to published procedures ${ }^{64}$. Briefly, monolayers of MDCK cells in $96-$ 
well cell culture plates were inoculated with $100 \mu \mathrm{L}$ of virus inoculum and infected for $2 \mathrm{~h}$. Cells were washed with serum-free medium and incubated with influenza A virus growth medium containing $2 \mu \mathrm{g} / \mathrm{mL}$ TPCK-trypsin (Sigma). At 3 days post-infection, cytopathic effect (CPE) of each well was counted.

Huh7 cells were transfected with the IL-32 $\gamma$ plasmid. At $16 \mathrm{~h}$ post-transfection, the cells were infected with HSV-1_GFP or A/WSN/33_GFP virus at 1 multiplicity of infection (MOI) (adsorption time, $1 \mathrm{~h}$ ). After infection, the medium was replaced with fresh medium, and cells were incubated for $24 \mathrm{~h}$. Treatment with ganciclovir (GCV) (Sigma) or a mixture of IFN- $\alpha(1000 \mathrm{U} / \mathrm{mL})$ and IFN- $\gamma(100 \mathrm{U} / \mathrm{mL})$ was used as a positive control. The cells were monitored for green fluorescence signals and images were taken with an inverted fluorescence microscope (Leica DM IL LED Fluo, Leica, Wetzlar, Germany) at $\times 100$ magnification.

Southern and Northern blot analyses. The replication of HBV was detected by Southern blot analysis ${ }^{65}$. Cells were harvested by scraping at 3 days posttransfection and lysed with $100 \mu \mathrm{L}$ HEPES buffer. Viral capsids were precipitated with PEG buffer and digested with SDS buffer containing Proteinase $\mathrm{K}$ at $37^{\circ} \mathrm{C}$ for $3 \mathrm{~h}$. Total viral DNA was separated on a $1 \%$ agarose gel at $100 \mathrm{~V}$ for $3 \mathrm{~h}$ and transferred to a nitrocellulose membrane (GE healthcare). To detect HBV DNA the membrane was hybridized with a highly purified [32 P]-labeled HBV probes. The level of HBV transcription was determined by Northern blot analysis as follows. Total RNA was extracted by using TRIzol reagent (Invitrogen) according to the manufacturer's protocol. Total RNA $(20 \mu \mathrm{g})$ was separated on a $1 \%$ formaldehyde agarose gel at $120 \mathrm{~V}$ for $3 \mathrm{~h}$ and transferred to a nitrocellulose membrane (GE healthcare) for $18 \mathrm{~h}$. To detect HBV-specific RNAs, the membrane was hybridized with a highly pure [32 $\left.{ }^{32}\right]$-labeled HBV probes. $18 \mathrm{~S}$ RNA was used as a loading control. Relative levels of HBV replication and transcription were calculated using a phosphorimager.

Nuclear run-on assay. To determine the rate of HBV transcription, nuclear run-on assay was performed ${ }^{31}$. Nuclear extracts were prepared from $\sim 1 \times 10^{7}$ cells $^{34}$ and mixed with an equal volume of $2 \times$ transcription reaction mix to final concentrations of $25 \mathrm{mM}$ Tris ( $\mathrm{pH}$ 8), $100 \mathrm{mM} \mathrm{KCl}, 7 \mathrm{mM} \mathrm{MgCl} 2,12.5 \%$ glycerol, $0.5 \mathrm{mM}$ each rATP, rGTP, rCTP and $0.25 \mathrm{mM}$ UTP, $10 \mathrm{mM}$ creatine phosphate, $1 \mathrm{mM}$ DTT, $10 \mu \mathrm{g} / \mathrm{mL}$ PMSF, and $250 \mu \mathrm{Ci}\left[{ }^{32} \mathrm{P}\right]$-labeled UTP. Transcription was carried out for $20 \mathrm{~min}$ at $26^{\circ} \mathrm{C}$. RNase-free DNase was then added and the samples were incubated for $10 \mathrm{~min}$ at $30^{\circ} \mathrm{C}$, followed by proteinase $\mathrm{K}$ digestion for $30 \mathrm{~min}$ at $45^{\circ} \mathrm{C}$. After addition of $1 / 10$ volume of $3 \mathrm{M} \mathrm{NaOAc}(\mathrm{pH} 4)$, total RNA was extracted with $500 \mu \mathrm{L}$ of phenol/chloroform and precipitated with ethanol at $-80^{\circ} \mathrm{C}$. Labeled RNA was resuspended in STE buffer (10 mM Tris [pH 8], $1 \mathrm{mM}$ EDTA, $140 \mathrm{mM} \mathrm{NaCl}$ ), and free nucleotides were removed by gel filtration on a Sephadex G-50 column. The labeled RNA was hybridized to membranes that contained the PCR-amplified HBV probes.

Real-time quantitative PCR. Real-time quantitative PCR was performed as follows ${ }^{38}$. Reverse transcription reactions were performed using $2 \mu \mathrm{g}$ of total RNA and MMLV reverse transcriptase (Intron Biotechnology) in the final reaction mixture volume of $20 \mu \mathrm{L}$. The synthesized cDNA was amplified by PCR under the following conditions: denaturation at $94^{\circ} \mathrm{C}$ for $5 \mathrm{~min}$, followed by 40 cycles of $94^{\circ} \mathrm{C}$ for $30 \mathrm{~s}$ and $72^{\circ} \mathrm{C}$ for $1 \mathrm{~min}$, and a final extension at $72^{\circ} \mathrm{C}$ for $5 \mathrm{~min}$ The sequences of specific primers used for real-time PCR are listed in Supplementary Table. 1. Real-time quantitative PCR amplification was performed in an ABI PRISM 7500 sequence detection system using the SYBR Green PCR master mix (Applied Biosystems). The results were expressed as an $\mathrm{n}$-fold difference relative to the calibrator $\left(\mathrm{RQ}=2^{-\Delta \Delta \mathrm{Ct}}\right)$.

Chromatin immunoprecipitation (ChIP) assay. ChIP assay was performed as follows ${ }^{10}$. Briefly, sonicated chromatin was pre-cleared using protein A-agarose and incubated with anti-HNF1a, anti-HNF4a, or normal rabbit IgG as a negative control. Immunoprecipitated DNA fragments were amplified by PCR. The sequences of primers used for ChIP assay are listed in Supplementary Table. 1.

Electrophoretic mobility shift assay (EMSA). EMSA was performed as follows ${ }^{60}$ Briefly, $2 \mu \mathrm{g}$ nuclear extracts of Huh7 cells were incubated with the gamma $\left[{ }^{32} \mathrm{P}\right]-$ labeled dsDNA probe for HNF4a binding. A set of probe sequences located in the

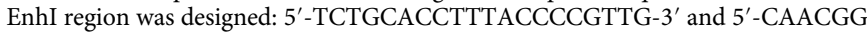
GGTAAAGGTGCAGA-3'. After binding on ice, the DNA-protein complex was analyzed by electrophoresis at a low temperature in $6 \%$ native polyacrylamide gel. Gel was dried at $70^{\circ} \mathrm{C}$ for $30 \mathrm{~min}$. The unlabeled competitor probe for HNF4a binding was added for $10 \mathrm{~min}$ before the addition of $\left[{ }^{32} \mathrm{P}\right]$-labeled probe.

Confocal microscopy. To evaluate the expression levels of IL-32 $\gamma$, HNF4a, and HNF1a, confocal microscopy analysis was performed ${ }^{60}$. Cells (Huh7 and PHHs) grown on cover slides were incubated overnight at $4{ }^{\circ} \mathrm{C}$ with primary antibodies (1:300) containing 3\% BSA in PBS. Huh7 cells were washed with PBS and incubated with secondary antibody conjugated with Alexa 488 or Alexa 568 for $1 \mathrm{~h}$ at room temperature. Cells were then washed 3 times with PBS at room temperature, and Toppro-3 (1:500) was added to stain nuclear DNA. The level of HBV infection in PHHs was determined by counting the HBcAg and HBsAg-positive cells under a fluorescence microscope.

Immunofluorescence microscopy of mouse tissues. Liver tissues were fixed in $10 \%$ formalin and embedded in paraffin. Slides with $5-\mu \mathrm{m}$ tissue sections were deparaffinized in xylene and rehydrated in ethanol. Antigen retrieval was performed in citrate buffer ( $\mathrm{pH}$ 6.0) using microwave treatment. Primary antibodies for HBcAg (HBV core protein, Dako) (1:800), IL-32 (1:100), and/or $\beta$-gal were incubated for $1 \mathrm{~h}$ in a humidified chamber at room temperature, followed by detection with secondary antibody (1:50) at room temperature by staining with a TSA Plus fluorescence kit (Perkin Elmer, Waltham, MA, USA). The slide was then placed in citrate buffer ( $\mathrm{pH}$ 6.0) and heated using a microwave oven. The images were acquired with a fluorescence microscope at $\times 100$ magnification.

Hydrodynamic injection and immunohistochemical analysis. Six-week-old male mice (BALB/C) were hydrodynamically injected with plasmids (HBV 1.2, IL-32 $\gamma$, and $\beta$-gal) in PBS $^{38}$. For co-localization assay, $10 \mu \mathrm{g}$ of each RFP and GFP plasmid was hydrodynamically injected into mouse liver. The volume equivalent to $10 \%$ of mouse body weight was injected via tail veins with high pressure within $4-6 \mathrm{~s}^{37}$. All mouse experiments were approved by the Animal Care Committee of the Konkuk University.

IL-32 $\gamma$ activity assay. Human THP-1 monocytic cell line and murine Raw 264.7 macrophage cell line were used. Cells were maintained in complete RPMI 1640 medium (Invitrogen) containing 10\% fetal bovine serum (Invitrogen) supplemented with $100 \mathrm{U} / \mathrm{mL}$ penicillin and $100 \mu \mathrm{g} / \mathrm{mL}$ streptomycin. THP-1 cells were washed with DPBS (Invitrogen) and seeded in 96-well tissue culture plates at $2 \times$ $10^{5}$ cells per well in $100 \mu \mathrm{L}$ per well complete RPMI 1640 medium and then incubated with either $100 \mu \mathrm{L}$ of culture medium (control) or $100 \mu \mathrm{L}$ of medium containing 100 or $200 \mathrm{ng} / \mathrm{mL}$ of recombinant human IL-32 $\gamma$ (final concentrations 50 and $100 \mathrm{ng} / \mathrm{mL}$, respectively; $\mathrm{YbdY}$ ) at $37^{\circ} \mathrm{C}$ in a $5 \% \mathrm{CO}_{2}$ humidified atmosphere. After $18 \mathrm{~h}$ of treatment, supernatants were collected, centrifuged at 2000 $\mathrm{rpm}$ and stored at $-20^{\circ} \mathrm{C}$ until cytokine assay by ELISA. Raw 264.7 cells were cultured in 96-well tissue culture plates at $5 \times 10^{4}$ cells per well overnight and then attached cells were used for assay. Raw 264.7 cells were washed and incubated with stimuli as described above. The supernatants from THP- 1 were evaluated for human IL-8 and those from Raw 264.7 for mouse TNF- $\alpha$. The amounts of human IL-8 and murine TNF- $\alpha$ were determined by sandwich ELISA according to the manufacturer's instructions (R\&D Systems, Minneapolis, MN, USA).

NF- $\kappa B$ luciferase assay and treatment with a NOS inhibitor. After cotransfection of Huh7 cells with pNF- $\kappa B-L u c(500 \mathrm{ng})$, control pcDNA3.1(+) (250 or $500 \mathrm{ng}$ ), and IL-32 $\gamma$ plasmid ( 250 or $500 \mathrm{ng}$ ), NF- $\mathrm{kB}$-dependent luciferase activity was measured using a Steady Glo-Luciferase assay system (Promega, Madison, WI, USA) according to the manufacturer's instructions. The values were normalized to $\beta$-galactosidase activity in the same cells. Data were obtained from at least three independent experiments. After co-transfection of Huh7 cells with the HBV 1.2 and IL-32 $\gamma$ plasmids, the nitric oxide synthase (NOS) inhibitor L-NAME (Sigma) was added (to 100 or $500 \mu \mathrm{M}$ ) for $72 \mathrm{~h}$. Southern blot analysis was performed to determine the HBV DNA levels.

Statistical analysis. Data were obtained from at least three independent experiments (mean \pm S.D.). All statistical calculations $(p<0.05, p<0.01$, and $p<0.001)$ were obtained using Microsoft Excel 2010 software or the Student's $t$-test in GraphPad Prism 5.

Data availability. The data supporting the findings of this study are available within the article and its Supplementary Information files and from the corresponding author on reasonable request.

Received: 25 September 2017 Accepted: 26 July 2018 Published online: 16 August 2018

\section{References}

1. Guidotti, L. G. et al. Cytotoxic T lymphocytes inhibit hepatitis B virus gene expression by a noncytolytic mechanism in transgenic mice. Proc. Natl Acad. Sci. USA 91, 3764-3768 (1994).

2. Guidotti, L. G. et al. Viral clearance without destruction of infected cells during acute HBV infection. Science 284, 825-829 (1999).

3. McClary, H., Koch, R., Chisari, F. V. \& Guidotti, L. G. Relative sensitivity of hepatitis B virus and other hepatotropic viruses to the antiviral effects of cytokines. J. Virol. 74, 2255-2264 (2000).

4. Ganem, D. \& Prince, A. M. Hepatitis B virus infection-natural history and clinical consequences. N. Engl. J. Med. 350, 1118-1129 (2004). 
5. Pasquetto, V., Wieland, S. F., Uprichard, S. L., Tripodi, M. \& Chisari, F. V. Cytokine-sensitive replication of hepatitis B virus in immortalized mouse hepatocyte cultures. J. Virol. 76, 5646-5653 (2002).

6. Wieland, S. F., Spangenberg, H. C., Thimme, R., Purcell, R. H. \& Chisari, F. V. Expansion and contraction of the hepatitis B virus transcriptional template in infected chimpanzees. Proc. Natl Acad. Sci. USA 101, 2129-2134 (2004).

7. Lin, S. J., Shu, P. Y., Chang, C., Ng, A. K. \& Hu, C. P. IL-4 suppresses the expression and the replication of hepatitis B virus in the hepatocellular carcinoma cell line Hep3B. J. Immunol. 171, 4708-4716 (2003).

8. Puro, R. \& Schneider, R. J. Tumor necrosis factor activates a conserved innate antiviral response to hepatitis B virus that destabilizes nucleocapsids and reduces nuclear viral DNA. J. Virol. 81, 7351-7362 (2007).

9. Xia, Y. et al. Interferon-gamma and tumor necrosis factor-alpha produced by $\mathrm{T}$ cells reduce the HBV persistence form, cccDNA, without cytolysis. Gastroenterology 150, 194-205 (2016).

10. Park, Y. K. et al. Cleaved c-FLIP mediates the antiviral effect of TNF-alpha against hepatitis B virus by dysregulating hepatocyte nuclear factors. $J$. Hepatol. 64, 268-277 (2016).

11. Shin, G. C. et al. Hepatocystin contributes to interferon-mediated antiviral response to hepatitis B virus by regulating hepatocyte nuclear factor 4alpha. Biochim. Biophys. Acta 1842, 1648-1657 (2014).

12. Kim, S. H., Han, S. Y., Azam, T., Yoon, D. Y. \& Dinarello, C. A. Interleukin32: a cytokine and inducer of TNFalpha. Immunity 22, 131-142 (2005).

13. Cho, K. S., Park, S. H., Joo, S. H., Kim, S. H. \& Shin, C. Y. The effects of IL-32 on the inflammatory activation of cultured rat primary astrocytes. Biochem. Biophys. Res. Commun. 402, 48-53 (2010).

14. Nishida, A., Andoh, A., Inatomi, O. \& Fujiyama, Y. Interleukin-32 expression in the pancreas. J. Biol. Chem. 284, 17868-17876 (2009).

15. Choi, J. D. et al. Identification of the most active interleukin-32 isoform. Immunology 126, 535-542 (2009).

16. Bae, S. et al. Characterizing antiviral mechanism of interleukin-32 and a circulating soluble isoform in viral infection. Cytokine 58, 79-86 (2012).

17. Zepp, J. A., Nold-Petry, C. A., Dinarello, C. A. \& Nold, M. F. Protection from RNA and DNA viruses by IL-32. J. Immunol. 186, 4110-4118 (2011).

18. Nold, M. F. et al. Endogenous IL-32 controls cytokine and HIV-1 production. J. Immunol. 181, 557-565 (2008).

19. Rasool, S. T. et al. Increased level of IL-32 during human immunodeficiency virus infection suppresses HIV replication. Immunol. Lett. 117, 161-167 (2008).

20. Li, W. et al. IL-32: a host proinflammatory factor against influenza viral replication is upregulated by aberrant epigenetic modifications during influenza A virus infection. J. Immunol. 185, 5056-5065 (2010).

21. Li, W. et al. Negative feedback regulation of IL-32 production by iNOS activation in response to dsRNA or influenza virus infection. Eur. J. Immunol. 39, 1019-1024 (2009).

22. $\mathrm{Li}$, W. et al. Activation of interleukin-32 pro-inflammatory pathway in response to influenza A virus infection. PLoS ONE 3, e1985 (2008).

23. $\mathrm{Li}$, Y. et al. Inducible Interleukin 32 (IL-32) exerts extensive antiviral function via selective stimulation of interferonlambda1 (IFN-lambda1). J. Biol. Chem. 288, 20927-20941 (2013).

24. Moolla, N., Kew, M. \& Arbuthnot, P. Regulatory elements of hepatitis B virus transcription. J. Viral Hepat. 9, 323-331 (2002).

25. Quasdorff, M. et al. A concerted action of HNF4alpha and HNF1alpha links hepatitis B virus replication to hepatocyte differentiation. Cell Microbiol. 10, 1478-1490 (2008).

26. Hosel, M. et al. Not interferon, but interleukin-6 controls early gene expression in hepatitis B virus infection. Hepatology 50, 1773-1782 (2009).

27. Kim, D. H., Kang, H. S. \& Kim, K. H. Roles of hepatocyte nuclear factors in hepatitis B virus infection. World J. Gastroenterol. 22, 7017-7029 (2016).

28. Lim, K. H. et al. Suppression of interferon-mediated anti-HBV response by single CpG methylation in the 5'-UTR of TRIM22. Gut 67, 166-178 (2018).

29. Mao, R. et al. Indoleamine 2,3-dioxygenase mediates the antiviral effect of gamma interferon against hepatitis B virus in human hepatocyte-derived cells. J. Virol. 85, 1048-1057 (2011).

30. Guidotti, L. G. \& Chisari, F. V. Immunobiology and pathogenesis of viral hepatitis. Annu. Rev. Pathol. 1, 23-61 (2006).

31. Tsui, L. V., Guidotti, L. G., Ishikawa, T. \& Chisari, F. V. Posttranscriptional clearance of hepatitis B virus RNA by cytotoxic T lymphocyte-activated hepatocytes. Proc. Natl Acad. Sci. USA 92, 12398-12402 (1995).

32. Heise, T., Guidotti, L. G., Cavanaugh, V. J. \& Chisari, F. V. Hepatitis B virus RNA-binding proteins associated with cytokine-induced clearance of viral RNA from the liver of transgenic mice. J. Virol. 73, 474-481 (1999).

33. Heise, T., Guidotti, L. G. \& Chisari, F. V. La autoantigen specifically recognizes a predicted stem-loop in hepatitis B virus RNA. J. Virol. 73, 5767-5776 (1999).

34. Banks, K. E. et al. Hepatocyte nuclear factor 3beta inhibits hepatitis B virus replication in vivo. J. Virol. 76, 12974-12980 (2002).

35. Quasdorff, M. \& Protzer, U. Control of hepatitis B virus at the level of transcription. J. Viral Hepat. 17, 527-536 (2010).
36. Zhao, Z. et al. Mucroporin-M1 inhibits hepatitis B virus replication by activating the mitogen-activated protein kinase (MAPK) pathway and downregulating HNF4alpha in vitro and in vivo. J. Biol. Chem. 287, 30181-30190 (2012).

37. Yang, P. L., Althage, A., Chung, J. \& Chisari, F. V. Hydrodynamic injection of viral DNA: a mouse model of acute hepatitis B virus infection. Proc. Natl Acad. Sci. USA 99, 13825-13830 (2002).

38. Park, E. S. et al. Hepatitis B virus inhibits liver regeneration via epigenetic regulation of urokinase-type plasminogen activator. Hepatology 58, 762-776 (2013).

39. Sebestyen, M. G. et al. Mechanism of plasmid delivery by hydrodynamic tail vein injection. I. Hepatocyte uptake of various molecules. J. Gene Med. 8, 852-873 (2006)

40. Zhu, H. Z., Wang, W., Feng, D. M., Sai, Y. \& Xue, J. L. Conditional gene modification in mouse liver using hydrodynamic delivery of plasmid DNA encoding Cre recombinase. FEBS Lett. 580, 4346-4352 (2006).

41. $\mathrm{Li}, \mathrm{N}$. et al. MxA inhibits hepatitis $\mathrm{B}$ virus replication by interaction with hepatitis B core antigen. Hepatology 56, 803-811 (2012).

42. Garcia-Sastre, A. \& Biron, C. A. Type 1 interferons and the virus-host relationship: a lesson in detente. Science 312, 879-882 (2006).

43. Wang, Z. et al. Inhibition of hepatitis B virus replication by cIAP2 involves accelerating the ubiquitin-proteasome-mediated destruction of polymerase. $J$. Virol. 85, 11457-11467 (2011).

44. Robek, M. D., Wieland, S. F. \& Chisari, F. V. Inhibition of hepatitis B virus replication by interferon requires proteasome activity. J. Virol. 76, 3570-3574 (2002).

45. Wieland, S. F., Eustaquio, A., Whitten-Bauer, C., Boyd, B. \& Chisari, F. V. Interferon prevents formation of replication-competent hepatitis $\mathrm{B}$ virus RNA-containing nucleocapsids. Proc. Natl Acad. Sci. USA 102, 9913-9917 (2005).

46. Robek, M. D., Boyd, B. S., Wieland, S. F. \& Chisari, F. V. Signal transduction pathways that inhibit hepatitis B virus replication. Proc. Natl Acad. Sci. USA 101, 1743-1747 (2004).

47. Gonzalez-Amaro, R. et al. Induction of tumor necrosis factor alpha production by human hepatocytes in chronic viral hepatitis. J. Exp. Med. 179, 841-848 (1994).

48. $\mathrm{Xu}, \mathrm{Q}$. et al. Increased interleukin-32 expression in chronic hepatitis B virusinfected liver. J. Infect. 65, 336-342 (2012).

49. Kim, Y. J. et al. Association of TNF-alpha promoter polymorphisms with the clearance of hepatitis B virus infection. Hum. Mol. Genet. 12, 2541-2546 (2003).

50. Qi, S. et al. Association of the -183 polymorphism in the IFN-gamma gene promoter with hepatitis B virus infection in the Chinese population. J. Clin. Lab. Anal. 19, 276-281 (2005).

51. Biermer, M., Puro, R. \& Schneider, R. J. Tumor necrosis factor alpha inhibition of hepatitis B virus replication involves disruption of capsid Integrity through activation of NF-kappaB. J. Virol. 77, 4033-4042 (2003).

52. Guidotti, L. G., McClary, H., Loudis, J. M. \& Chisari, F. V. Nitric oxide inhibits hepatitis B virus replication in the livers of transgenic mice. J. Exp. Med. 191, $1247-1252$ (2000).

53. Kuo, C. J. et al. A transcriptional hierarchy involved in mammalian cell-type specification. Nature 355, 457-461 (1992).

54. Moschen, A. R. et al. Interleukin-32: a new proinflammatory cytokine involved in hepatitis $\mathrm{C}$ virus-related liver inflammation and fibrosis. Hepatology 53, 1819-1829 (2011).

55. Severgnini, M. et al. A rapid two-step method for isolation of functional primary mouse hepatocytes: cell characterization and asialoglycoprotein receptor based assay development. Cytotechnology 64, 187-195 (2012).

56. Kwon, S. Y. et al. Identification and characterization of clevudine-resistant mutants of hepatitis B virus isolated from chronic hepatitis B patients. J. Virol. 84, 4494-4503 (2010).

57. Lim, K. H. et al. HBx-induced NF-kappaB signaling in liver cells is potentially mediated by the ternary complex of HBx with p22-FLIP and NEMO. PLoS ONE 8, e57331 (2013).

58. Kang, J. W. et al. A proinflammatory cytokine interleukin-32beta promotes the production of an anti-inflammatory cytokine interleukin-10. Immunology 128, e532-e540 (2009).

59. Lee, S. et al. Interleukin-32 gamma specific monoclonal antibody and developing IL-32 specific ELISA. Hybridoma 29, 501-509 (2010).

60. Lim, K. H. et al. RPS3a over-expressed in HBV-associated hepatocellular carcinoma enhances the HBx-induced NF-kappaB signaling via its novel chaperoning function. PLoS ONE 6, e22258 (2011).

61. Desai, P. \& Person, S. Incorporation of the green fluorescent protein into the herpes simplex virus type 1 capsid. J. Virol. 72, 7563-7568 (1998).

62. Wu, N. C. et al. Systematic identification of H274Y compensatory mutations in influenza A virus neuraminidase by high-throughput screening. J. Virol. 87, 1193-1199 (2013).

63. Cheong, W. C. et al. Influenza A virus NS1 protein inhibits the NLRP3 inflammasome. PLoS ONE 10, e0126456 (2015). 
64. Szretter, K. J., Balish, A. L. \& Katz, J. M. Influenza: propagation, quantification, and storage. Curr. Protoc. Microbiol. https://doi.org/10.1002/ 0471729256.mc15g01s3 (2006).

65. Ahn, S. H. et al. Substitution at rt269 in hepatitis B virus polymerase is a compensatory mutation associated with multi-drug resistance. PLOS ONE 10, e0136728 (2015)

\section{Acknowledgements}

This study was supported by the National Research Foundation of Korea (NRF) grants funded by the Korea government (NRF-2017R1A2B3006335 and NRF-2016R1A5A2012284), and by the Korea Health Technology R\&D Project through the Korea Health Industry Development Institute (KHIDI), funded by the Ministry of Health \& Welfare (No. HI17C0874).

\section{Author contributions}

Study conception and design: D.H.K., E.-S.P. and K.-H.K. (Konkuk). Acquisition of data: D.H.K., E.-S.P., A.R.L., S.P., W.-C.C., Y.K.P., S.H.A., H.S.K., J.H.W., Y.N.H. and B.J. Analysis and interpretation of data: M.J.S., S.H.P. and S.-H.K. Material support: Y.K.P., S.H.A., H.S.K., A.R.L., S.P., J.H.W., Y.N.H., B.J., D.-S.K. and K.-H.K. (Catholic). Obtained funding: K.-H.K. (Konkuk) and E.-S.P. Drafted the manuscript: D.H.K., E.-S.P. and K.-H.K. (Konkuk).

\section{Additional information}

Supplementary Information accompanies this paper at https://doi.org/10.1038/s41467018-05782-5.
Competing interests: The authors declare no competing interests.

Reprints and permission information is available online at http://npg.nature.com/ reprintsandpermissions/

Publisher's note: Springer Nature remains neutral with regard to jurisdictional claims in published maps and institutional affiliations.

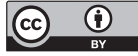

Open Access This article is licensed under a Creative Commons Attribution 4.0 International License, which permits use, sharing, adaptation, distribution and reproduction in any medium or format, as long as you give appropriate credit to the original author(s) and the source, provide a link to the Creative Commons license, and indicate if changes were made. The images or other third party material in this article are included in the article's Creative Commons license, unless indicated otherwise in a credit line to the material. If material is not included in the article's Creative Commons license and your intended use is not permitted by statutory regulation or exceeds the permitted use, you will need to obtain permission directly from the copyright holder. To view a copy of this license, visit http://creativecommons.org/ licenses/by/4.0/.

(C) The Author(s) 2018 